NBER WORKING PAPER SERIES

\title{
IDIOSYNCRATIC SHOCKS AND THE ROLE OF NONCONVEXITIES IN PLANT AND AGGREGATE INVESTMENT DYNAMICS
}

\author{
Aubhik Khan \\ Julia Thomas \\ Working Paper 12845 \\ http://www.nber.org/papers/w12845
NATIONAL BUREAU OF ECONOMIC RESEARCH
1050 Massachusetts Avenue
Cambridge, MA 02138
January 2007

We thank Robert King, Narayana Kocherlakota, John Leahy, Robert Lucas, Marcelo Veracierto, seminar audiences at Columbia, Michigan, Pompeu Fabra, Stanford, Wharton and the Federal Reserve Banks of Minneapolis, Philadelphia, Richmond and St. Louis, participants in the April 2006 Penn State Financial Constraints or Technological Differences Conference and the October 2006 Study Center Gerzensee Microeconomic Adjustment and Macroeconomic Dynamics Conference, as well as session participants at the 2004 Midwest Macro and SED meetings for useful comments and suggestions. Thomas thanks the Alfred P. Sloan Foundation and the National Science Foundation (grant \#0318163) for research support. The views expressed here are those of the authors and do not represent the views of Federal Reserve Bank of Philadelphia or the Federal Reserve System. The views expressed herein are those of the author(s) and do not necessarily reflect the views of the National Bureau of Economic Research.

(C) 2007 by Aubhik Khan and Julia Thomas. All rights reserved. Short sections of text, not to exceed two paragraphs, may be quoted without explicit permission provided that full credit, including $\odot$ notice, is given to the source. 
Idiosyncratic Shocks and the Role of Nonconvexities in Plant and Aggregate Investment Dynamics Aubhik Khan and Julia Thomas

NBER Working Paper No. 12845

January 2007

JEL No. E22,E32

\begin{abstract}
$\underline{\text { ABSTRACT }}$
We study a model of lumpy investment wherein establishments face persistent shocks to common and plant-specific productivity, and nonconvex adjustment costs lead them to pursue generalized (S,s) investment rules. We allow persistent heterogeneity in both capital and total factor productivity alongside low-level investments exempt from adjustment costs to develop the first model consistent with available evidence on establishment-level investment rates. Examining the implications of lumpy investment for aggregate dynamics in this setting, we find that they remain substantial when factor supply considerations are ignored, but are quantitatively irrelevant in general equilibrium. The substantial implications of general equilibrium extend beyond the dynamics of aggregate series. While the presence of idiosyncratic shocks makes the time-averaged distribution of plant-level investment rates largely invariant to market-clearing movements in real wages and interest rates, we show that the dynamics of plants' investments differ sharply in their presence. Thus, model-based estimations of capital adjustment costs involving panel data may be quite sensitive to the assumption about equilibrium. Our analysis also offers new insights about how nonconvex adjustment costs influence investment at the plant. When establishments face idiosyncratic productivity shocks consistent with existing estimates, we find that nonconvex costs do not cause lumpy investments, but act to eliminate them.
\end{abstract}

\author{
Aubhik Khan \\ Research Department \\ Federal Reserve Bank of Philadelphia \\ Ten Independence Hall \\ Philadelphia, PA 19106 \\ mail@aubhik-khan.net \\ Julia Thomas \\ Research Department \\ Federal Reserve Bank of Philadelphia \\ Ten Independence Mall \\ Philadelphia, PA 19106-1574 \\ and NBER \\ mail@juliathomas.net
}




\section{Introduction}

Over the past fifteen years, an influential body of research has developed the argument that, in order to understand cyclical fluctuations in aggregate investment, we must explicitly examine changes in the underlying distribution of capital across establishments. This growing literature challenges the usefulness of smooth aggregative models for business cycle research, emphasizing that there are important nonlinearities in aggregate investment originating from nonconvexities at the establishment level. In particular, it has been argued that nonconvex costs of adjustment lead establishments to adjust capital infrequently in the form of lumpy investments and that occasional synchronization in the timing of establishments' investments can sharply influence the dynamics of the aggregate series. As explained by Caballero and Engel (1999), a large aggregate shock in such a setting may lead to a substantial change in the number of establishments undertaking capital adjustment. This, in turn, implies a time-varying elasticity of aggregate investment demand with respect to shocks. The further claim is that such nonlinearities help explain the data.

The substantial heterogeneity that characterizes $(S, s)$ models of capital adjustment has largely dissuaded researchers in the lumpy investment literature from undertaking general equilibrium analysis. ${ }^{1}$ One early exception to this was the dynamic stochastic general equilibrium model of Khan and Thomas (2003), where nonconvex adjustment costs caused plants to adopt optimal $(S, s)$ decision rules with respect to capital. There, the aggregate nonlinearities predicted by previous partial equilibrium studies were present when real wages and interest rates were held fixed, but they disappeared in general equilibrium. Proponents of lumpy investment have remained unconvinced by the finding, however, partly because there were important discrepancies in the model's microeconomic implications relative to the data. At the heart of the lumpy investment debate lies the distribution of capital across establishments. As the distribution of investment arising in our early model differed sharply from that in the data, implying a similar mismatch for the distribution of capital itself, researchers were led to question the relevance of its aggregate implications.

\footnotetext{
${ }^{1}$ Examples of partial equilibrium $(S, s)$ models include Caballero and Engel (1999), Caballero, Engel and Haltiwanger (1995), Cooper, Haltiwanger and Power (1999) and Cooper and Haltiwanger (2006). Veracierto (2002) provides a general equilibrium analysis of plant-level $(S, s)$ policies caused by irreversible investment. Bachman, Caballero and Engel (2006) study a version of our general equilibrium lumpy investment model , but follow a different calibration strategy, as is discussed in section 6. Gourio and Kashyap (2006) modify the Thomas (2002) environment to include random machine breakdowns and less uncertainty in capital adjustment costs.
} 
One important limitation of the first-generation DSGE lumpy analysis was an assumption that differences in capital were the sole source of heterogeneity across plants. Although it could generate lumpy investments, the abstraction from persistent differences in plantspecific productivity prevented the theory from usefully addressing a richer set of recently documented establishment-level facts. ${ }^{2}$ For example, Cooper and Haltiwanger's (2006) summary of investment patterns in the LRD reveals negative capital adjustments among 10 percent of plants in the average year, while the model failed to generate any. Moreover, as is the convention throughout the lumpy literature, there was a stark assumption regarding the incidence of nonconvex adjustment costs, with these costs applying to all capital adjustments irrespective of their size. As a result, the model reproduced the observed frequency of large positive investment episodes (spikes) only by dramatically overstating the frequency of nearzero (inactive) episodes.

Confronting these issues, this paper reconsiders whether plant-level nonconvexities are an essential element lacking in our standard models of the business cycle, this time in an equilibrium setting where the resulting distribution of capital is empirically viable. Here, we take two important steps away from the first-generation model to construct a model that is quantitatively consistent with the available evidence on establishment-level capital adjustment. First, we allow for persistent differences across plants not only in their capital stocks but also in their total factor productivities. Next, we further generalize the model to permit plants to undertake low levels of investment without incurring adjustment costs. As we evaluate the aggregate implications of nonconvex capital adjustment costs in this more realistic setting, our approach will be distinguished by a series of simple comparisons between our lumpy investment economy versus an otherwise identical (nested) economy without adjustment frictions. By undertaking these controlled comparisons, we can attribute any differences we find entirely to the difference in adjustment technologies.

Before exploring aggregate results, we first verify that our model satisfies two prerequisites for a useful study. We begin by confirming its consistency with the features of the plant investment distribution that motivate our current work. Next, we confirm that the lumpy investment technology therein has a substantial influence on dynamics that does not evaporate with aggregation. Specifically, we show that, in partial equilibrium (that is, with real wage and interest rates fixed at their steady-state values), nonconvex adjustment costs at the plant sharply increase skewness and kurtosis in the distribution of aggregate investment rates.

\footnotetext{
${ }^{2}$ It has also been suggested that additional sources of persistent heterogeneity may reinforce the aggregate effects of lumpy microeconomic adjustment, and that their omission in our earlier work biased results against aggregate implications.
} 
Having established our model's consistency with previous predictions of aggregate nonlinearities throughout the partial equilibrium lumpy literature, we trace these features to large changes in the target capital stocks adopted by adjusting plants (changes along the intensive margin) in response to aggregate shocks that, in turn, induce large changes in the numbers of plants actively undertaking these adjustments (changes along the extensive margin). In particular, our environment generates asymmetries in the average distribution of plants over capital, alongside rising adjustment hazards implying that the fractions of plants paying fixed costs to undertake adjustment rise in the distance from the relevant target capitals. We show that this combination leads to asymmetric changes along the extensive margin that amplify aggregate responses to positive shocks, but dampen responses to negative shocks. Finally, we also confirm that, in partial equilibrium, aggregate investment rates are less volatile and more persistent in the presence of nonconvex adjustment costs, as consistent with the aggregate smoothing emphasized in Bachman, Caballero and Engel's (2006) recent equilibrium work on lumpy investment and in related work on investment irreversibilities by Bertola and Caballero (1994). By delaying capital adjustment for some establishments, fixed costs at the establishment level deliver gradual changes in aggregate investment. Thus, partial equilibrium estimation may tend to emphasize these costs because, like convex adjustment costs, they deliver persistence in aggregate investment rates that would otherwise be absent, bringing them closer to the data.

Despite the sharp improvement in our current model's ability to reproduce investment patterns in the microeconomic data, our aggregate findings here reinforce those isolated in our previous lumpy investment studies. Microeconomic lumpiness continues to have perceptible effects on aggregate investment dynamics only when equilibrium factor supply considerations are ignored. General equilibrium itself matters tremendously in shaping aggregate dynamics. First, it is extremely effective in smoothing changes in aggregate series, yielding investment rates close to the postwar US data in both their cyclical variability and persistence, irrespective of capital adjustment costs. Second, it dampens much of the movement along the extensive margin that would otherwise distinguish the lumpy investment economy, leaving no trace of aggregate nonlinearities. However, this is not a deficiency of our theoretical environment relative to its empirical counterpart; it is a success. In fact, we show that the near-zero skewness and excess kurtosis in the distribution of aggregate investment rates arising from our general equilibrium models (both lumpy and smooth) matches the third and fourth moments from the aggregate data reasonably well, and far more closely than does the partial equilibrium lumpy model.

Whether nonconvex adjustment costs cause only a fraction of all plants to (unconstrainedly) adjust their capital stocks in any period (in the lumpy model), or whether all 
plants adjust their stocks in every period (in a control model without adjustment frictions), households' preferences for consumption smoothing imply equilibrium movements in relative prices that sharply restrain changes in the target capitals to which these plants adjust in response to aggregate disturbances. Moreover, these dampened changes along the intensive margin immediately imply reduced changes in the value that plants in the lumpy investment economy place on adjustment, thus eliminating large extensive margin changes. Without these large movements in the numbers of adjusting plants, the nonlinearities distinguishing the lumpy investment economy disappear. As a result, our model economy achieves through modest movements along two margins the same aggregate investment dynamics that appear in the frictionless control model through the intensive margin alone.

Our development of a DSGE model consistent with richer aspects of the establishmentlevel data has led us to some additional new results regarding the influence of nonconvex adjustment costs, idiosyncratic risk and general equilibrium upon microeconomic investment behavior that we believe may be of independent interest. First, we find that intertemporal changes in the cross-sectional distribution of plant investment rates are sharply dampened in general equilibrium. Although the reallocation of investment goods across plants in response to idiosyncratic shocks is unaffected by equilibrium (as it generates no changes in aggregate investment), we show that the micro-elasticity of response to aggregate shocks is greatly reduced when the associated equilibrium movements in relative prices are permitted to feed back into establishments' decisions. This indicates that equilibrium analysis is essential for understanding investment dynamics even at the most disaggregated level, particularly in times of large aggregate disturbances. Thus, it is precisely during those episodes where partial equilibrium lumpy researchers (e.g., Caballero, Engel and Haltiwanger (1995), Caballero and Engel (1999), Cooper and Haltiwanger (2006)) have argued the distribution of establishments over capitals is essential to understanding aggregate dynamics that a partial equilibrium analysis most distorts the true distribution.

Second, we find that the microeconomic role of nonconvex capital adjustment costs can change substantially in the presence of persistent idiosyncratic risk. When plant-specific productivity shocks are volatile relative to aggregate shocks, as suggested by the data, nonconvex costs no longer cause the plant-level investment spikes that are the hallmark of lumpy investment. Rather, their primary role shifts to one of eliminating some of these spikes, as is necessary to move the model-implied average cross-sectional distribution in line with the data. These costs now take on a secondary role in reproducing a stark asymmetry in the occurrence of positive versus negative investment (spikes). Noting that each of these effects also arises in the presence of investment irreversibilities, and under combinations of irreversibilities and convex capital adjustment costs, this finding suggests that there actually 
may be no distinct role for nonconvex costs even at the microeconomic level. As such, it may be extremely difficult to correctly disentangle the importance of nonconvex costs, relative to other adjustment frictions, from the establishment-level investment data.

\section{Model}

In our model economy, there are both fixed costs of capital adjustment and persistent differences in plant-specific productivity, which together lead to substantial heterogeneity in production. In this section, we describe the economy beginning with production units, then follow with households and equilibrium. Next, using a simple implication of equilibrium, we characterize the capital adjustment decisions of production units as a two-sided generalized $(S, s)$ policy. This decision rule for investment is what distinguishes the model from the stochastic neoclassical growth model.

\subsection{Production and capital adjustment}

We assume a large number of production units. Each establishment produces its output using predetermined capital stock $k$ and labor $n$, via an increasing and concave production function, $F$ :

$$
y=z \varepsilon F(k, n) .
$$

Here, $z$ reflects stochastic total factor productivity common across plants, while $\varepsilon$ is plantspecific productivity. For convenience, we assume that $z$ is a Markov chain, $z \in\left\{z_{1}, \ldots, z_{N_{z}}\right\}$, where

$$
\operatorname{Pr}\left(z^{\prime}=z_{j} \mid z=z_{i}\right) \equiv \pi_{i j} \geq 0,
$$

and $\sum_{j=1}^{N_{z}} \pi_{i j}=1$ for each $i=1, \ldots, N_{z}$. Similarly, we assume that $\varepsilon \in\left\{\varepsilon_{1}, \ldots, \varepsilon_{N_{\varepsilon}}\right\}$, where

$$
\operatorname{Pr}\left(\varepsilon^{\prime}=\varepsilon_{m} \mid \varepsilon=\varepsilon_{l}\right) \equiv \pi_{l m}^{\varepsilon} \geq 0
$$

and $\sum_{m=1}^{N_{\varepsilon}} \pi_{l m}^{\varepsilon}=1$ for each $l=1, \ldots, N_{\varepsilon}$.

In each period, a plant is defined by its predetermined stock of capital, $k \in \mathbf{R}_{+}$, its idiosyncratic productivity level, $\varepsilon \in \mathcal{E} \equiv\left\{\varepsilon_{1}, \ldots, \varepsilon_{N_{e}}\right\}$, and its fixed cost associated with (non-exempted) capital adjustment, $\xi \in[0, \bar{\xi}]$, which is denominated in units of labor. Given the current aggregate state of the economy, the plant chooses its current level of employment, production occurs, and its workers are paid. Next, the plant chooses its investment; in doing so, it chooses whether it will pay or avoid its current adjustment cost. 
The plant's capital stock evolves according to $\gamma k^{\prime}=(1-\delta) k+i$, where $i$ is its current investment and $\delta \in(0,1)$ is the rate of capital depreciation. ${ }^{3}$ After current production, the plant can undertake an unconstrained investment only upon payment of its fixed adjustment cost, $\xi$. Specifically, by forfeiting $\omega \xi$ units of current output, where $\omega$ denotes the real wage rate, the plant can invest to any future capital, $k^{\prime} \in \mathbf{R}_{+}$. Alternatively, because fixed costs do not apply to adjustments that are sufficiently minor relative to the existing capital stock, the plant can avoid its fixed cost by selecting a constrained investment, $i \in[a k, b k]$, where $a \leq 0 \leq b$. In this case, the plant achieves future capital $k^{\prime} \in \Lambda(k) \subseteq \mathbf{R}_{+}$, where

$$
\Lambda(k) \equiv\left[\frac{1-\delta+a}{\gamma} k, \frac{1-\delta+b}{\gamma} k\right] .
$$

For the plant, capital adjustment involves a nonconvexity; conditional on undertaking an unconstrained adjustment, the cost $\xi$ entailed is independent of the scale of adjustment. At the same time, we assume that $\xi$ varies across plants and over time for any given plant. Each period, every plant draws a cost from the time-invariant distribution $G:[0, \bar{\xi}] \rightarrow[0,1]$. As a result, given its end-of-period stock of capital, a plant's current adjustment cost has no implication for its future adjustment. Thus, it is sufficient to describe differences across plants by their idiosyncratic productivity, $\varepsilon$, and capital, $k$. We summarize the distribution of plants over $(\varepsilon, k)$, using the probability measure $\mu$ defined on the Borel algebra, $\mathcal{S}$, for the product space $\mathbf{S}=\mathcal{E} \times \mathbf{R}_{+}$. The aggregate state of the economy is then described by $(z, \mu)$, and the distribution of plants evolves over time according to a mapping, $\Gamma$, from the current aggregate state; $\mu^{\prime}=\Gamma(z, \mu)$. We will define this mapping below.

Let $v^{1}\left(\varepsilon_{l}, k, \xi ; z_{i}, \mu\right)$ represent the expected discounted value of a plant entering the period with $\left(\varepsilon_{l}, k\right)$ and drawing an adjustment cost $\xi$, when the aggregate state of the economy is $\left(z_{i}, \mu\right)$. We state the dynamic optimization problem for the typical plant using a functional equation defined by (2) - (4). First we define the beginning of period expected value of a plant, prior to the realization of its fixed cost draw, but after the determination of $\left(\varepsilon_{l}, k ; z_{i}, \mu\right)$ :

$$
v^{0}\left(\varepsilon_{l}, k ; z_{i}, \mu\right) \equiv \int_{0}^{\bar{\xi}} v^{1}\left(\varepsilon_{l}, k, \xi ; z_{i}, \mu\right) G(d \xi) .
$$

Assume that $d_{j}\left(z_{i}, \mu\right)$ is the discount factor applied by plants to their next-period expected value if aggregate productivity at that time is $z_{j}$ and current productivity is $z_{i}$. (Except where necessary for clarity, we suppress the indices for current aggregate and plant productivity below.) The plant's profit maximization problem, which takes as given the evolution

\footnotetext{
${ }^{3}$ Throughout the paper, primes indicate one-period-ahead values, and all variables measured in units of output are deflated by the level of labor-augmenting technological progress, which implies output growth at the rate $\gamma-1$ along the balanced growth path.
} 
of the plant distribution, $\mu^{\prime}=\Gamma(z, \mu)$, is then described by

$$
\begin{aligned}
& v^{1}(\varepsilon, k, \xi ; z, \mu)=\max _{n}[z \varepsilon F(k, n)-\omega(z, \mu) n+(1-\delta) k \\
& \left.\quad+\max \left\{-\xi \omega(z, \mu)+\max _{k^{\prime} \in \mathbf{R}_{+}} r\left(\varepsilon, k^{\prime} ; z, \mu^{\prime}\right), \max _{k^{\prime} \in \Lambda(k)} r\left(\varepsilon, k^{\prime} ; z, \mu^{\prime}\right)\right\}\right],
\end{aligned}
$$

where $r\left(\varepsilon, k^{\prime} ; z, \mu^{\prime}\right)$ represents the continuation value associated with any future capital stock:

$$
r\left(\varepsilon, k^{\prime} ; z, \mu^{\prime}\right) \equiv-\gamma k^{\prime}+\sum_{j=1}^{N_{z}} \pi_{i j} d_{j}(z, \mu) \sum_{m=1}^{N_{e}} \pi_{l m}^{\varepsilon} v^{0}\left(\varepsilon_{m}, k^{\prime} ; z_{j}, \mu^{\prime}\right) .
$$

Given $(\varepsilon, k, \xi)$ and the equilibrium wage rate $\omega(z, \mu)$, the plant chooses current employment $n$. Next, the plant decides upon either an unconstrained or a constrained choice of its capital stock for next period. The unconstrained choice, in the first term of the binary maximum above, requires payment of the fixed labor cost of capital adjustment. However, if $k^{\prime} \in \Lambda(k)$ is selected, the second term in the binary maximum applies, and this cost is avoided. Rather than subtracting investment from current profits, we adopt an equivalent but notationally more convenient approach in (3); there, the value of nondepreciated capital augments current profits, and the plant is seen to repurchase its capital stock each period. Since adjustment costs do not affect the choice of current employment, we denote the common employment selected by all type $(\varepsilon, k)$ plants using $N(\varepsilon, k ; z, \mu)$. Further, let $K(\varepsilon, k, \xi ; z, \mu)$ represent the choice of capital for the next period by plants of type $(\varepsilon, k)$ with adjustment cost $\xi$.

\subsection{Households}

The economy is populated by a unit measure of identical households. Household wealth is held as one-period shares in plants, which we denote using the measure $\lambda{ }^{4}$ Given the prices they receive for their current shares, $\rho_{0}(\varepsilon, k ; z, \mu)$, and the real wage they receive for their labor effort, $\omega(z, \mu)$, households determine their current consumption, $c$, hours worked, $n^{h}$, as well as the numbers of new shares, $\lambda^{\prime}\left(\varepsilon^{\prime}, k^{\prime}\right)$, to purchase at prices $\rho_{1}\left(\varepsilon^{\prime}, k^{\prime} ; z, \mu\right)$. The

\footnotetext{
${ }^{4}$ Households also have access to a complete set of state-contingent claims. However, as there is no heterogeneity across households, these assets are in zero net supply in equilibrium. Thus, for brevity, we do not explicitly model them.
} 
lifetime expected utility maximization problem facing each of them is listed below.

$$
\begin{gathered}
W(\lambda ; z, \mu)=\max _{c, n^{h}, \lambda^{\prime}}\left[U\left(c, 1-n^{h}\right)+\beta \sum_{j=1}^{N_{z}} \pi_{i j} W\left(\lambda^{\prime} ; z_{j}, \mu^{\prime}\right)\right] \\
\text { subject to } \\
c+\int_{\mathbf{S}} \rho_{1}\left(\varepsilon^{\prime}, k^{\prime} ; z, \mu\right) \lambda^{\prime}\left(d\left[\varepsilon^{\prime} \times k^{\prime}\right]\right) \leq \omega(z, \mu) n^{h}+\int_{\mathbf{S}} \rho_{0}(\varepsilon, k ; z, \mu) \lambda(d[\varepsilon \times k]) .
\end{gathered}
$$

Let $C(\lambda ; z, \mu)$ describe the household choice of current consumption, $N^{h}(\lambda ; z, \mu)$ the current allocation of time to working, and $\Lambda^{h}\left(\varepsilon^{\prime}, k^{\prime}, \lambda ; z, \mu\right)$ the quantity of shares purchased in plants that begin the next period with productivity $\varepsilon^{\prime}$ and $k^{\prime}$ units of capital.

\subsection{Recursive equilibrium}

A recursive competitive equilibrium is a set of functions,

$$
\left(\omega,\left(d_{j}\right)_{j=1}^{N_{z}}, \rho_{0}, \rho_{1}, v^{1}, N, K, W, C, N^{h}, \Lambda^{h}\right)
$$

such that plants and households maximize their expected values, and the markets for assets, labor and output clear:

1. $v^{1}$ satisfies $(2)-(4)$, and $(N, K)$ are the associated policy functions for plants.

2. $W$ satisfies (5), and $\left(C, N^{h}, \Lambda^{h}\right)$ are the associated policy functions for households.

3. $\Lambda^{h}\left(\varepsilon_{m}, k^{\prime}, \mu ; z, \mu\right)=\mu^{\prime}\left(\varepsilon_{m}, k^{\prime}\right)$, for each $\left(\varepsilon_{m}, k^{\prime}\right) \in \mathbf{S}$.

4. $N^{h}(\mu ; z, \mu)=\int_{\mathbf{S}}\left[N(\varepsilon, k ; z, \mu)+\int_{0}^{\bar{\xi}} \xi \mathcal{J}\left(\frac{\gamma K(\varepsilon, k, \xi ; z, \mu)-(1-\delta) k}{k}\right) G(d \xi)\right] \mu(d[\varepsilon \times k])$, where $\mathcal{J}(x)=0$ if $x \in[a, b] ; \mathcal{J}(x)=1$ otherwise.

5. $C(\mu ; z, \mu)=\int_{\mathbf{S}}\left[z \varepsilon F(k, N(\varepsilon, k ; z, \mu))-\int_{0}^{\bar{\xi}}(\gamma K(\varepsilon, k, \xi ; z, \mu)-(1-\delta) k) G(d \xi)\right] \mu(d[\varepsilon \times k])$.

6. $\mu^{\prime}\left(\varepsilon_{m}, B\right)=\int_{\left\{\left(\varepsilon_{l}, k, \xi\right) \mid K\left(\varepsilon_{l}, k, \xi ; z, \mu\right) \in B\right\}} \pi_{l m}^{\varepsilon} G(d \xi) \mu\left(d\left[\varepsilon_{l} \times k\right]\right)$, for all $\left(\varepsilon_{m}, B\right) \in \mathcal{S}$, defines $\Gamma$. 


\section{$2.4(S, s)$ decision rules}

Using $C$ and $N$ to describe the market-clearing values of household consumption and hours worked satisfying conditions 4 and 5 above, it is straightforward to show equilibrium requires that $\omega(z, \mu)=\frac{D_{2} U(C, 1-N)}{D_{1} U(C, 1-N)}$ and that $d_{j}(z, \mu)=\frac{\beta D_{1} U\left(C_{j}^{\prime}, 1-N_{j}^{\prime}\right)}{D_{1} U(C, 1-N)}$. We may then compute equilibrium by solving a single Bellman equation that combines the plant-level profit maximization problem with these equilibrium implications of household utility maximization. Defining $p$ as the price plants use to value current output, we have the following two conditions.

$$
\begin{aligned}
p(z, \mu) & =D_{1} U(C, 1-N) \\
\omega(z, \mu) & =\frac{D_{2} U(C, 1-N)}{p(z, \mu)}
\end{aligned}
$$

A reformulation of (2) - (4) then yields an equivalent description of a plant's dynamic problem. Suppressing the arguments of the price functions and defining $\Lambda(k)$ as in (1),

$$
\begin{aligned}
& V^{1}(\varepsilon, k, \xi ; z, \mu)=\max _{n}[(z \varepsilon F(k, n)-\omega n+(1-\delta) k) p \\
& \left.\quad+\max \left\{-\xi \omega p+\max _{k^{\prime} \in \mathbf{R}_{+}} R\left(\varepsilon, k^{\prime} ; z, \mu^{\prime}\right), \max _{k^{\prime} \in \Lambda(k)} R\left(\varepsilon, k^{\prime} ; z, \mu^{\prime}\right)\right\}\right],
\end{aligned}
$$

where

$$
\begin{gathered}
R\left(\varepsilon, k^{\prime} ; z, \mu^{\prime}\right) \equiv-\gamma k^{\prime} p+\beta \sum_{j=1}^{N_{z}} \pi_{i j} \sum_{l=1}^{N_{e}} \pi_{l m}^{\varepsilon} V^{0}\left(\varepsilon_{m}, k^{\prime} ; z_{j}, \mu^{\prime}\right) \\
V^{0}(\varepsilon, k ; z, \mu) \equiv \int_{0}^{\bar{\xi}} V^{1}(\varepsilon, k, \xi ; z, \mu) G(d \xi) .
\end{gathered}
$$

Equations (8) - (10) will be the basis of our numerical solution of the economy. This solution exploits several results that we now derive. First, note that plants choose labor $n=N(\varepsilon, k ; z, \mu)$ to solve $z \varepsilon D_{2} F(k, n)=\omega(z, \mu)$. Next, we examine the capital choice of a type $(\varepsilon, k)$ plant drawing adjustment $\operatorname{cost} \xi$. Define the value associated with the unconstrained capital choice, $E(\varepsilon, z, \mu)$, and that associated with the constrained choice, $E^{C}(\varepsilon, k, z, \mu)$, as follow:

$$
\begin{aligned}
E(\varepsilon, z, \mu) & \equiv \max _{k^{\prime} \in \mathbf{R}_{+}} R\left(\varepsilon, k^{\prime} ; z, \mu^{\prime}\right) \\
E^{C}(\varepsilon, k, z, \mu) & \equiv \max _{k^{\prime} \in \Lambda(k)} R\left(\varepsilon, k^{\prime} ; z, \mu^{\prime}\right) .
\end{aligned}
$$

Next, define the plant's target capital as the unconstrained choice of $k^{\prime}$ solving the right-hand side of (11). 
Note that the solution to the unconstrained problem in (11) is independent of both $k$ and $\xi$, but not $\varepsilon$, given persistence in plant-specific productivity. As a result, all plants sharing the same current productivity $\varepsilon$ that pay their fixed costs to make unconstrained capital adjustments will choose a common target capital for the next period, $k^{\prime}=k^{*}(\varepsilon, z, \mu)$, and achieve a common gross value of unconstrained adjustment, $E(\varepsilon, z, \mu)$. By contrast, plants that do not pay adjustment costs, instead undertaking constrained capital adjustments solving (12), will choose future capital that may depend on their current capital, $k^{\prime}=$ $k^{C}(\varepsilon, k, z, \mu)$. (The exception occurs for plants with $k^{*}(\varepsilon, z, \mu) \in \Lambda(k)$; for such plants, the constraint in (12) does not bind, and the target capital is achieved without incurring an adjustment cost.)

Referring again to the functional equation in (8), it is clear that a plant will absorb its fixed cost to undertake an unconstrained adjustment if the net value of achieving the target capital, $E(\varepsilon, z, \mu)-\xi \omega p$, is at least as great as the continuation value under constrained adjustment, $E^{C}(\varepsilon, k, z, \mu)$. It follows immediately that a plant of type $(\varepsilon, k)$ will undertake unconstrained capital adjustment if its fixed cost, $\xi$, lies at or below some $(\varepsilon, k)$-specific threshold value. In particular, let $\widehat{\xi}(\varepsilon, k ; z, \mu)$ describe the fixed cost that leaves a type $(\varepsilon, k)$ plant indifferent between these investment options:

$$
-p(z, \mu) \widehat{\xi}(\varepsilon, k ; z, \mu) \omega(z, \mu)+E(\varepsilon, z, \mu)=E^{C}(\varepsilon, k, z, \mu) .
$$

Next, define $\xi^{T}(\varepsilon, k ; z, \mu) \equiv \min \{\bar{\xi}, \widehat{\xi}(\varepsilon, k ; z, \mu)\}$, so that $0 \leq \xi^{T}(\varepsilon, k ; z, \mu) \leq \bar{\xi}$. Any plant with an adjustment cost at or below its type-specific threshold, $\xi^{T}(\varepsilon, k ; z, \mu)$, will pay the fixed cost and adjust to its target capital.

Using the target and constrained capital choices identified above, alongside the threshold adjustment costs, the plant-level decision rule for capital may be conveniently summarized as follows. Any establishment identified by the plant-level state vector $(\varepsilon, k, \xi ; z, \mu)$ will begin the subsequent period with a capital stock given by

$$
k^{\prime}=K(\varepsilon, k, \xi ; z, \mu)= \begin{cases}k^{*}(\varepsilon, z, \mu) & \text { if } \quad \xi \leq \xi^{T}(\varepsilon, k ; z, \mu) \\ k^{C}(\varepsilon, k, z, \mu) & \text { if } \quad \xi>\xi^{T}(\varepsilon, k ; z, \mu) .\end{cases}
$$

Thus, within each group of plants sharing a common $(\varepsilon, k)$, fraction $G\left(\xi^{T}(\varepsilon, k ; z, \mu)\right)$ pay their labor-denominated fixed costs to undertake an unconstrained capital adjustment. It then follows that the market-clearing levels of consumption and work hours required to 
determine $p$ and $\omega$ using (6) and (7) are given by:

$$
\begin{aligned}
C= & \int_{\mathbf{S}}\left(z \varepsilon F(k, N(\varepsilon, k ; z, \mu))-G\left(\xi^{T}(\varepsilon, k ; z, \mu)\right)\left[\gamma k^{*}(\varepsilon, z, \mu)-(1-\delta) k\right]\right. \\
& \left.-\left[1-G\left(\xi^{T}(\varepsilon, k ; z, \mu)\right)\right]\left[\gamma k^{C}(\varepsilon, k, z, \mu)-(1-\delta) k\right]\right) \mu(d[\varepsilon \times k]), \\
N= & \int_{\mathbf{S}}\left[N(\varepsilon, k ; z, \mu)+\int_{0}^{\xi^{T}(\varepsilon, k ; z, \mu)} \xi G(d \xi)\right] \mu(d[\varepsilon \times k]) .
\end{aligned}
$$

Finally, based on (14), we can now describe the evolution of the plant distribution, $\mu^{\prime}=\Gamma(z, \mu)$. First, define the indicator function $\overline{\mathcal{J}}(x)=1$ for $x=0 ; \overline{\mathcal{J}}(x)=0$ for $x \neq 0$.

Informally, for each $\left(\varepsilon_{m}, \widehat{k}\right) \in \mathcal{S}$,

$$
\begin{aligned}
\mu^{\prime}\left(\varepsilon_{m}, \widehat{k}\right)= & \sum_{l=1}^{N_{\varepsilon}} \pi_{l m}^{\varepsilon}\left[\overline{\mathcal{J}}\left(\widehat{k}-k^{*}\left(\varepsilon_{l}, z, \mu\right)\right) \int G\left(\xi^{T}\left(\varepsilon_{l}, k ; z, \mu\right)\right) \mu\left(\varepsilon_{l}, d k\right)\right. \\
& \left.+\int\left[1-G\left(\xi^{T}\left(\varepsilon_{l}, k ; z, \mu\right)\right)\right] \overline{\mathcal{J}}\left(\widehat{k}-k^{C}\left(\varepsilon_{l}, k, z, \mu\right)\right) \mu\left(\varepsilon_{l}, d k\right)\right] .
\end{aligned}
$$

Consider the cases of $\widehat{k}=k^{*}\left(\varepsilon_{l}, z, \mu\right)$, for each given $\varepsilon_{l}, l=1, \ldots, N_{\varepsilon}$. The first line of equation (17) represents those plants $\left(\varepsilon_{l}, k\right)$ that pay their fixed costs to adjust to this target. However, our law of motion must also reflect those plants that reach $\widehat{k}=k^{*}\left(\varepsilon_{l}, z, \mu\right)$ without paying fixed costs. For such plants, $k^{C}\left(\varepsilon_{l}, k, z, \mu\right)=k^{*}\left(\varepsilon_{l}, z, \mu\right)$, so $\xi^{T}\left(\varepsilon_{l}, k ; z, \mu\right)=0$. Thus, they are a subset of the plants avoiding fixed costs in the second line of (17), those with current capital such that $k^{*}\left(\varepsilon_{l}, z, \mu\right) \in \Lambda(k)$. Next, consider the cases of $\widehat{k} \neq k^{*}\left(\varepsilon_{l}, z, \mu\right)$. Those plants reflected in the second line for which $k^{*}\left(\varepsilon_{l}, z, \mu\right) \notin \Lambda(k)$ are plants that face either a binding upper constraint on their capital choice (with $k<\frac{\gamma}{1-\delta+b} k^{*}\left(\varepsilon_{l}, z, \mu\right)$ ) or a binding lower constraint (with $\left.k>\frac{\gamma}{1-\delta+a} k^{*}\left(\varepsilon_{l}, z, \mu\right)\right)$. Of this group, those with $k^{C}\left(\varepsilon_{l}, k, z, \mu\right)=\widehat{k}$ begin the next period with $\widehat{k}$.

\section{Calibration}

We evaluate the plant-level and aggregate implications of nonconvex capital adjustment costs using several numerical experiments across which we vary the stochastic process for idiosyncratic shocks to plants' total factor productivity and the parameterization of capital adjustment costs. All other production parameters, as well as preferences, are held constant throughout. Each experiment is based on a 10,000-period model simulation, and the same random draw of aggregate productivity is used in each. Below, we discuss functional forms and parameter values for technology and preferences that are identical across models. 
Thereafter, in section 3.2, we explain the choice of idiosyncratic shocks and the distribution of capital adjustment costs. The description of our numerical method is provided in Appendix A.

\subsection{Common parameters}

Across our model economies, we assume that the representative household's period utility is the result of indivisible labor (Hansen (1985), Rogerson (1988)): $u(c, L)=\log c+\varphi L$, and the establishment-level production function takes a Cobb-Douglas form, $z \varepsilon F(k, N)=$ $z \varepsilon k^{\alpha} N^{\nu}$. We fix the length of a period to correspond to one year, allowing us to use evidence on establishment-level investment in selecting parameters governing the distributions of adjustment costs and idiosyncratic productivities below.

Model parameters, other than those involving idiosyncratic shocks and adjustment costs, are selected to ensure agreement with observed long-run values for key postwar U.S. aggregates in a nested frictionless version of our model without capital adjustment costs described in Appendix B. As proven in lemma 2 of this appendix, macroeconomic aggregates are insensitive to the presence of idiosyncratic productivity differences in the absence of capital adjustment costs. This allows us to choose parameter values for technology and preferences that are consistent with empirical counterparts before specifying an idiosyncratic shock process. For these parameters, we apply the same values to the lumpy investment model. We are able to use this approach because the aggregate first moments across our model economies are extremely similar.

The mean growth rate of technological progress is chosen to imply a 1.6 percent average annual growth rate of real per capita output, and the discount factor, $\beta$, is then set to imply an average real interest rate of 4 percent. Given the rate of technological progress, the depreciation rate, $\delta$, is selected to match an average investment-to-capital ratio of 10 percent, corresponding to the average value for the private capital stock between 1954 and 2002 in the U.S. Fixed Asset Tables. Labor's share is then set to 0.64 as in Prescott (1986); given this value, capital's share of output is determined by targeting an average capitalto-output ratio of 2.353 as in the data. Next, the parameter governing the preference for leisure, $\varphi$, is taken to imply an average of one-third of available time spent in market work. Table 1 lists the resulting parameter values.

In specifying our exogenous stochastic process for aggregate productivity, we begin by assuming a continuous shock following a mean zero $\mathrm{AR}(1)$ process in logs: $\log z^{\prime}=\rho_{z} \log z+$

$\eta_{z}^{\prime}$ with $\eta_{z}^{\prime} \sim N\left(0, \sigma_{\eta_{z}}^{2}\right)$. Next, we estimate the values of $\rho_{z}$ and $\sigma_{\eta_{z}}$ from Solow residuals measured using NIPA data on US real GDP and private capital, together with the total employment hours series constructed by Prescott, Ueberfeldt, and Cociuba (2005) from 
CPS household survey data, over the years 1959-2002. Finally, we discretize the resulting productivity process using a grid with 11 shock realizations; $N_{z}=11$.

\subsection{Plant-specific shocks and adjustment costs}

The remaining parameters involve the distribution of plant-specific productivity and the adjustment costs facing plants in the lumpy investment economy. We determine idiosyncratic shocks $\left(\varepsilon_{i}\right)_{i=1}^{N_{\varepsilon}}$ and the Markov Chain determining their evolution $\left(\pi_{i j}^{\varepsilon}\right)_{i, j=1}^{N_{\varepsilon}}$ by discretizing a $\log$-normal process, $\log \varepsilon^{\prime}=\rho_{\varepsilon} \log \varepsilon+\eta_{\varepsilon}^{\prime}$ using 15 values $\left(N_{\varepsilon}=15\right)$. To maintain controlled comparisons, the same stochastic process is applied to both the frictionless and the lumpy investment models. In the latter, fixed costs of investment are assumed to be drawn from a uniform distribution, $G(\xi)=\xi / \bar{\xi}$, and the range of investment rates that do not incur such costs is assumed to be symmetric around 0; in other words, $|a|=b$.

There is little agreement about the persistence of the idiosyncratic shock process, $\rho_{\varepsilon}$. (Compare, for example, the values in Comin and Phillipon (2005) to those of Cooper and Haltiwanger (2006).) Given this, we simply set it equal to the persistence of the aggregate shock, $\rho_{\varepsilon}=\rho_{z}{ }^{5} \quad$ Next, the remaining plant-level parameters $\left(\sigma_{\eta_{\varepsilon}}, \bar{\xi}, b\right)$ are selected to best match the empirical average distribution of plant investment rates, as summarized by Cooper and Haltiwanger (2006).

Constructing their own plant capital series using data on retirements and investment from the Longitudinal Research Database, Cooper and Haltiwanger provide a detailed set of time-averaged moments on plants' investment rates, which are reproduced in the shaded row of Table 2. They define any plant with an investment rate (ratio of investment to capital) less than 1 percent in absolute value as inactive. Positive investment rates are those at or exceeding 1 percent, while negative investment rates are those falling at or below -0.01 . Finally, positive spikes are investment rates exceeding 0.2 , and negative spikes are observations of $\frac{i}{k}<-0.2$.

Several features of the time-averaged plant data are prerequisites for our study. First, investment inactivity is relatively rare, occurring among only 8 percent of plants on average. Next, there is a sharp asymmetry in positive versus negative investment rates; in the average year, roughly 82 percent of plants actively raise their capital stocks. Finally, the columns summarizing observations of investment spikes indicate not only extreme investment episodes occurring among a nontrivial fraction of establishments (roughly 20 percent) in the tails of the average plant distribution, but also right skewness. Here again we see a sharp asymmetry; positive spikes are observed 10 times as often as negative spikes.

\footnotetext{
${ }^{5}$ In a previous version of this paper, we instead selected a much lower persistence, $\rho_{\varepsilon}=0.53$, taken from Cooper and Haltiwanger (2002). Our findings here are entirely unaffected by the change.
} 
Before proceeding, we discuss our reasons for assuming a region of capital adjustment that is exempt from adjustment costs. Throughout the lumpy investment literature thus far, it has been assumed that all active adjustments to a plant's capital stock incur fixed costs. Given that assumption, we show in the next section that the inclusion of idiosyncratic productivity shocks is not sufficient to yield consistency with the average distribution of investment rates in the plant-level data. Specifically, the traditional lumpy investment model matches the average occurrence of large positive and negative investment episodes only by substantially exaggerating the frequency of near-zero investment episodes. One possible explanation for this tension in reconciling the theory with microeconomic data is that, in reality, fixed adjustment costs apply only to those investments that are comparatively large relative to a plant's existing capital. Alternatively, it may be reasonable to suppose that the fixed costs associated with relatively large capital adjustments, such as building a new structure, are substantially greater than those associated with minor ones, such as installing a new computer. We adopt a rough proxy for these distinctions by permitting some low-level capital adjustments that are exempt from fixed costs. This generalization of the traditional lumpy investment framework allows our model to overcome the tension noted above, making it the first to succeed in matching the average distribution of plant investment rates.

\section{Prerequisites}

\subsection{Consistency with microeconomic data}

A prerequisite for our current study is that our environment reproduce the key aspects of the microeconomic data described above. In Table 2, we evaluate the microeconomic performance of our model, comparing it to that of the traditional lumpy investment model previously studied by Khan and Thomas (2003). ${ }^{6} \quad$ There, all non-zero investment rates were subject to fixed adjustment costs $(b=0)$, and there were no plant-specific productivity disturbances $\left(N_{\varepsilon}=1, \sigma_{\eta_{\varepsilon}}=0\right)$. Row 1 presents the results for this special case of our current model when the upper support of the adjustment cost distribution alone is selected to best match the LRD data.

The traditional lumpy model reproduces only one aspect of the micro data, the frequency of positive investment spikes. There, some plants repeatedly draw relatively high fixed costs, and hence forego capital adjustment, for several consecutive periods. Typically, when such

\footnotetext{
${ }^{6}$ These moments from the cross-sectional distribution in each model's steady state match closely with corresponding time-averages taken over long general equilibrium model simulations. While partial equilibrium simulations yield similar results, they are more so when plants' individual investment decisions are more influenced by idiosyncratic relative to aggregate disturbances.
} 
a plant finally takes action, its effective capital stock lies far below the target to which it invests, a result of ongoing depreciation and technological progress. This explains why fixed costs cause positive investment spikes in this environment. ${ }^{7}$ However, in the average year, there is no force leading any plant to lower its target capital, so no establishment has capital exceeding its target. As a result, this simple model cannot generate any of the negative investment (and hence negative spikes) seen in the average cross-sectional distribution from the LRD. While the model does achieve large asymmetries, it does so in a trivial sense. Moreover, as noted above, it suffers a stark trade-off in generating sufficient observations of positive spikes versus positive investment rates.

The trade-off in reproducing observations of investment spikes versus inactivity is a common difficulty among quantitative models of lumpy investment, (see, for example, Cooper and Haltiwanger (2006)). To achieve the former, generally there must be a sufficient number of plants that refuse to pay their adjustment cost draws for several consecutive periods and thus see their actual capital stocks move far from their targets. This, in turn, means that the upper support on adjustment costs must be sufficiently high to ensure only a small fraction of plants pay their fixed costs in the typical period. When adjustment costs apply to all non-zero investments, this immediately implies far too much investment inactivity. Roughly 79 percent of plants are inactive in the traditional lumpy model versus 8 percent in the data and, in turn, the model delivers far too few observations of positive investment, as reflected in column 4 . This problem persists with the introduction of plant-specific productivity shocks; again, inactivity exceeds 75 percent when observations of positive spikes match those in the data.

The sharp disparities between the moments summarizing actual plant-level investment patterns and those arising in the traditional lumpy model of our previous work have motivated the extensions we have undertaken here in arriving at our current model. When plants face idiosyncratic productivity shocks, those shifting from relatively high productivities to relatively low ones can find themselves with too much capital and choose to undertake negative investment. Moreover, if that drop in relative productivity is sufficiently large, it may result in a negative spike. Next, the tension between reproducing the empirical observations of spikes versus inaction is alleviated by allowing for the possibility that not all investment is subject to fixed costs. In this case, plants not paying their adjustment costs may exhibit active investments, while nonetheless having their activities sufficiently constrained that they will eventually undertake an investment spike. As seen in row 2, roughly 75 percent

\footnotetext{
${ }^{7}$ While fixed costs cause investment spikes here, they can have precisely the opposite effect in environments where plant-level productivity is associated with substantial idiosyncratic risk. We revisit this issue in section 7.2 .
} 
of plants now exhibit positive investments on average in our model, almost matching the 82 percent seen in the data.

Aside from the moments of the time-averaged investment rate distribution presented in table 2, we also report our model's fit to some moments of establishment-level investment dynamics that were not targets in our calibration. First, we find that the variability of plant investment rates is reasonably well reproduced by our general equilibrium model. Simulating 1000 plants over 10, 000 periods, the standard deviation of the typical plant's investment rate is 24.4 percent in our model, while it is 33.7 percent in the LRD (Cooper and Haltiwanger (2006)). Next, we consider the measure developed by Gourio and Kashyap (2006) to gauge the importance of the extensive margin in explaining changes in investment spikes. Using the LRD, they find that the correlation between the number of plants experiencing positive investment spikes and the total investment in these plants (as a fraction of aggregate capital) is 87 percent. Our model also predicts a sizeable role for the extensive margin in explaining spikes, with a corresponding correlation of 66.9 percent.

\subsection{Partial equilibrium aggregate nonlinearities and smoothing}

We begin our study of the implications of nonconvex capital adjustment costs by confirming that, in partial equilibrium, our model of lumpy investment exhibits important nonlinearities that survive aggregation. As almost all of the existing analyses of lumpy investment have been conducted in partial equilibrium, this exercise is necessary to establish our model's consistency with these existing studies abstracting from market clearing movements in real wages and interest rates. ${ }^{8}$ To confirm the large potential lumpy investment has for reshaping our model's aggregate dynamics, we simulate a partial equilibrium version of the model and compare its results to those in the corresponding frictionless model (distinguished only by its upper support on adjustment costs, $\bar{\xi}=0$ ) in panel A of Table 3. Both models are subject to the same 10,000 period random draw of aggregate shocks. In choosing a margin along which to compare them, we follow the empirical investment literature, which has focused on changes in investment rates (that is, movements in the unfiltered ratio of investment to capital).

\subsubsection{Nonlinearities}

The frictionless model serving as our control is an element of the set of models that Caballero, Engel and Haltiwanger (1995) and Caballero (1999) refer to as linear, in that it is a special case of a quadratic capital adjustment cost model. These authors term such models

\footnotetext{
${ }^{8}$ See, for example, Caballero and Engel (1999), Caballero, Engel and Haltiwanger (1995) and Cooper, Haltiwanger and Power (1999).
} 
linear based on the result that, if shocks are normally distributed, then so too are investment rates. Consistent with this, our frictionless model generates approximately zero skewness and excess kurtosis in aggregate investment rates. ${ }^{9}$ In the lumpy investment model, by contrast, nonconvex capital adjustment at the plant-level leads to a distribution of aggregate investment rates that is both sharply right-skewed and fat-tailed. This is the central and well-known nonlinearity in models of lumpy investment that has motivated such interest in their aggregate implications, summarized by Caballero (1999) as follows. "What is the aspect of the data that makes these models better than linear ones at explaining aggregate investment dynamics? ... it is the flexible cyclical elasticity of the increasing hazard model which allows it to better capture the high skewness and kurtosis imprinted on aggregate data by brisk investment recoveries."

In fact, lumpy investment in our model increases skewness roughly 3-fold and kurtosis more than 15-fold relative to the frictionless control. This vivid evidence of nonlinearity in panel A establishes that our model is capable of delivering an aggregate role for lumpy investment similar to that found in previous partial equilibrium studies and summarized in Caballero's (1999) survey. However, if one compares the two rows of this panel to the near-zero third and fourth moments in the shaded row representing postwar U.S. investment rates, it appears that the additional skewness and kurtosis generated by lumpy investment does not improve model fit, but instead moves the model-implied investment series further from the data. ${ }^{10}$

\subsubsection{Smoothing}

While the lumpy investment literature has primarily focused on aggregate nonlinearities, there is also a smoothing aspect associated with fixed capital adjustment costs that has been emphasized in the recent work of Bachman, Caballero and Engel (2006). We conclude our discussion of the partial equilibrium panel in table 3 by noting from its first two columns that our model is consistent with this more recent focus. This may come as little surprise, given an analogous finding by Bertola and Caballero (1994) in the context of investment

\footnotetext{
${ }^{9}$ The faint suggestion of nonlinearity, more precisely skewness, that we observe in the frictionless model arises from the log-normal distribution of aggregate shocks and decreasing returns to scale in the aggregate production technology.

${ }^{10}$ These aggregate investment rate moments are similar whether we use the private sector captial stock, as we do here, or the business capital stock. In that case, persistence and standard deviation are 0.777 and 0.011, respectively, while skewness and excess kurtosis are -0.053 and -0.619 . Nonetheless, these moments of the data do depend upon the level of aggregation. Examining investment rates from two-digit U.S. manufacturing industries, Caballero and Engel (1999) find skewness and kurtosis of 0.61 and 0.74 , respectively, for equipment and 0.76 and 0.87 for structures.
} 
irreversibilities.

It is well-understood that, in partial equilibrium, the frictionless model lacks necessary smoothing. In contrast to the aggregate data, its aggregate investment rate is both far too volatile and negatively auto-correlated. With real wages and interest rates held fixed, aggregate capital in this model is entirely determined by the previous period's aggregate productivity. Corresponding to this, the full response in aggregate investment demand takes place immediately at the date of an aggregate shock. Thus, while productivity and hence aggregate capital are persistent, investment is not. Turning to the second row, note that lumpy investment improves model fit in these two columns by removing a substantial fraction of the excess variability and introducing some persistence.

In this smoothing respect, nonconvex costs in the lumpy investment model take on the same aggregate role that convex capital adjustment costs have historically held in representative-firm neoclassical investment models. In such models, convex costs smooth aggregate capital adjustment along the intensive margin by inducing all plants to undertake concurrent, but gradual, capital adjustment. In our model, by contrast, the aggregate adjustment is gradualized through the extensive margin, because fixed adjustment costs imply that only a fraction of plants adjust their capital in any period. ${ }^{11}$

Because they stagger the adjustments undertaken by individual plants in response to aggregate shocks, nonconvex adjustment costs at the micro-level protract adjustments in aggregate capital. More specifically, fixed costs induce inaction among plants with relatively high current costs or capital close to their target value. Thus, in the aggregate, investment demand initially responds less to a change in aggregate productivity than in the frictionless model without adjustment costs. However, because aggregate productivity changes are very persistent, many initially inactive plants undertake capital adjustments in subsequent periods. Thus, in partial equilibrium, fixed capital adjustment costs make aggregate investment both less variable and more persistent. However, despite these improvements, the partial equilibrium lumpy model continues to exhibit more than 10 times the variability, and far too little persistence, relative to the aggregate data.

\subsubsection{Extensive margin}

Figure 1 provides further evidence of the substantial changes lumpy investment implies for our model's aggregate dynamics when relative prices are fixed at their steady state values.

\footnotetext{
${ }^{11}$ In contrast to the aggregate nonlinearities that are our primary focus, the smoothing effect of nonconvex costs (associated with a reduction in the standard deviation of aggregate series) survives in general equilibrium if these costs are sufficiently large, in an otherwise plausibly calibrated model. We explore this issue further in section 6 .
} 
The top panel shows the histogram of aggregate investment rates over the partial equilibrium simulation in the lumpy model; the bottom panel shows the corresponding histogram for the control model without adjustment frictions. Note first the abruptness in the frictionless model's investment rate distribution. Looking then to the top panel, we see that fixed adjustment costs smooth away some of this abruptness, as consistent with our discussion above. Moreover, while the distribution in the lower panel appears roughly symmetric, the inclusion of lumpy investment in the upper panel causes the distribution to lean rightward, and shifts more mass into the tails.

The added kurtosis arises from the fact that aggregate investment in the partial equilibrium lumpy model is more responsive to large aggregate shocks than to small ones, as consistent with the time-varying elasticity of investment rates stressed by previous authors in this literature. This follows directly from the rising shape of the hazards that govern the fractions of plants undertaking (unconstrained) capital adjustment in a period. As will be clear below, this shape implies that small shifts in the hazards yield minimal changes in the numbers of adjusting plants, while larger shifts can generate disproportionately large changes in these numbers. The increased skewness arises from the fact that the model's investment series is more responsive to large positive shocks than it is to large negative ones. As we will explain, this happens because there are usually more plants concentrated on the lower ramps of the adjustment hazards, carrying too little capital relative to their targets, versus the upper ramps associated with excess capital.

Figure 2 illustrates the skewness arising in the partial equilibrium lumpy investment model by showing the responses in aggregate capital following a two standard deviation positive shock to aggregate total factor productivity versus a same-sized negative shock. There, we plot capital's percent deviation from steady state in the lumpy investment and frictionless models under the assumption that the wage and real interest rate remain at their steady-state values. In response to the positive shock in period 20, the rise in the lumpy model's aggregate capital stock, 58 percent, is roughly the same as in the frictionless model, 59 percent. However, following the negative shock in period 40, the aggregate capital stock falls by 37 percent in the frictionless model, but by only 20 percent in the lumpy investment model. Thus, while nonconvex adjustment costs do smooth the responses in aggregate investment and thus capital to shocks, their effect is very nonlinear; responses to positive shocks are hardly affected, while responses to negative shocks are greatly dampened.

Skewness in the lumpy investment model's aggregate responses is caused by asymmetric changes in the numbers of plants undertaking (unconstrained) adjustments to their capital stocks. To explore this asymmetry, we must examine how the distribution of plants over capital evolves in response to aggregate disturbances. For expositional ease, we abstract from 
plant productivity shocks in this discussion to consider the effects of the two shocks above in a common productivity version of our model. In this case, the endogenous aggregate state contains a one-dimensional distribution of plants over capital, and, within any period, there is a single adjustment hazard determining the fractions of plants that pay their fixed costs to adjust from each capital level to one common target. This adjustment hazard and the corresponding steady state distribution are shown in figure 3. The highest capital value at which the distribution has positive mass is the target, $k^{*}$, just below 1.38 , which is adopted by all plants that pay their fixed adjustment costs, absent changes in aggregate productivity. The dashed curve, which may be read off the right vertical axis, shows adjustment rates as a function of capital.

Note that the adjustment hazard rises in the distance between current capital and the capital stocks associated with the target, (the capital stocks from which a plant can reach $k^{*}$ for next period without suffering an adjustment cost, $\left.k \in\left[\frac{\gamma}{1-\delta+b} k^{*}, \frac{\gamma}{1-\delta-b} k^{*}\right]\right)$. The hazard takes this rising shape because plants with capital further from the target are willing to suffer larger fixed costs to correct their stocks, and thus have higher probabilities of capital adjustment. The lowest capital level held by any plant is 0.653 ; those entering the period with this stock adjust with full probability. We define the aggregate adjustment rate in our model as the population-weighted sum of the fractions of plants adjusting to their target from each current capital, which is 0.223 in the steady-steady of the common productivity model shown in figure 3. Finally, notice that, because both physical and economic depreciation continually erode nonadjusted capital stocks, plants enter the average period concentrated along the left ramp of the hazard with capital at or below the target. ${ }^{12}$ This is essential to the partial equilibrium lumpy model's asymmetric responses to positive versus negative shocks, as may be seen in figure 4 .

The left panel of figure 4 illustrates the extensive margin response to the two standard deviation rise in productivity from above in figure 2 , beginning with the bolded steady state distribution and hazard of figure 3, and continuing to hold relative prices fixed at steady state. Because changes in aggregate productivity are expected to persist, the positive shock causes a large rise in the expected marginal product of capital that in turn raises target capital sharply, to roughly 2.06. This leads the adjustment hazard to shift rightward, recentering at the much higher capitals associated with the new target. Given that plants have all entered the period located along the left ramp of the steady state hazard (with capital at or below the steady state target), this shift increases the gap between actual and

\footnotetext{
${ }^{12}$ More generally, in our model with plant-specific productivity shocks, there is an adjustment hazard associated with each plant productivity level. Nonetheless, given mean-reversion in the shocks, the downward pressure of depreciation and technological progress continues to imply disproportionate concentrations of plants along the left ramps of the hazards.
} 
target capital for each of them, raising the value they place on capital adjustment. With plants of each type now willing to pay larger fixed costs, adjustment rates increase sharply, and the total number of adjusting plants jumps to 0.986. This rise along the extensive margin reinforces the intensive-margin rise in the average investment undertaken by each adjusting plant. As a result, aggregate capital rises by far more than it would in the absence of an increase in adjustment rates. For the common productivity model, the 72 percent rise in the aggregate capital stock exceeds the 59 percent rise in the frictionless model (where idiosyncratic productivity differences do not affect aggregate responses).

By contrast, the right panel of figure 4 illustrates how the equivalent fall in aggregate productivity leads to a sharp decrease in adjustment rates, again beginning with the bolded steady state distribution and hazard. With the drop in expected future productivity, the resulting fall in target capital, to 0.926 , moves it down into the existing plant distribution, and below the capital stock actually held by almost all plants. As a result, the fraction of plants for which adjustment is sufficiently valuable to offset the associated fixed costs declines markedly. This decline is most pronounced near the middle of the distribution, where current capital, once adjusted for depreciation and exogenous technological progress, is closest to the target capital stock for next period. As a result, the adjustment hazard takes on a $U$ shape over the mass of plants and, overall, the number of adjusting plants falls from its average of 0.223 to 0.159 . This fall in the adjustment rate offsets some of the decline in aggregate capital that would otherwise occur with the fall in target capital, leading the aggregate capital stock to fall by only 13 percent, far less than the 37 percent fall in the frictionless model.

In sum, we have seen that the lumpy investment model can exhibit asymmetry in its aggregate responses to shocks, and thus skewness in the distribution of aggregate investment rates, because rightward versus leftward shifts in its adjustment hazards generate asymmetric changes along the extensive margin in the number of adjusting plants. These changes are sufficiently large to drive pronounced aggregate nonlinearities in partial equilibrium, because aggregate shocks are followed by sharp changes in target capital that cause large shifts in adjustment hazards. Returning to our full lumpy model with heterogeneity in both capital and productivity, this explains the sharp response following the positive shock in figure 2 (which, despite its adjustment frictions, very nearly reaches that in the frictionless control model) and its markedly dampened response following the negative shock, and thus the skewed distribution of partial equilibrium investment rates seen in the top panel of figure $1 .{ }^{13}$

\footnotetext{
${ }^{13}$ Evidence of aggregate nonlinearity under partial equilibrium is even more extreme in the common productivity case of our model analyzed above. There, skewness and kurtosis are 1.90 and 5.29, respectively. Plant-specific productivity shocks on their own substantially reduce the lumpy investment model's potential for aggregate nonlinearities, because their presence implies more dispersion in the average distribution of
} 
In the section below, we will explore the extent to which these large dynamic effects persist when we relax the fixed real wage and interest rate assumption maintained throughout this section.

\section{$5 \quad$ Aggregate Results}

Having established our model's consistency with essential features of the microeconomic data, as well as the existence of aggregate nonlinearities in partial equilibrium that make it comparable to existing studies in the literature, we now examine its aggregate results.

\subsection{Model fit}

Figure 5 presents the general equilibrium counterpart to the distribution of aggregate investment rates in the lumpy versus frictionless model examined in figure 1. Here, we report simulation results based on the same 10,000 period random draw of aggregate shocks as before, this time solving the models in equilibrium. Note that both model economies' investment rates are greatly dampened by market-clearing movements in real wage and interest rates; thus, the range of investment rates in figure 5 is nearly 10 times more compressed relative to figure 1 . Nonetheless, differences in the equilibrium histograms appear minimal, with little evidence of added skewness or kurtosis in the lumpy investment panel.

These observations are confirmed by the second and higher moments presented in panel B of Table 3. There, we see an unambiguous improvement in model fit as we move from the partial equilibrium lumpy investment row of panel A to its general equilibrium counterpart in panel B. Persistence increases sharply, nearly reaching the empirical autocorrelation, while the excessive volatility in column 2 is virtually eliminated. Moreover, comparing the GE lumpy model to its PE counterpart, we see that equilibrium dramatically reduces the skewness and excess kurtosis in the distribution of aggregate investment rates, bringing the model far closer to the actual series. Viewing the four columns as a whole, the simulated aggregate investment rate series matches its counterpart in the data relatively well when the effects of equilibrium are included in the lumpy investment environment, and far less so when these effects are ignored.

Although the general equilibrium lumpy investment model yields empirically viable aggregate investment dynamics, comparison of the two rows within panel B reveals that the nonconvex investment technology faced by plants has no role in this success. Consistent

plants over capital, as well as greater symmetry in the typical concentration of plants along the left versus right ramps of adjustment hazards. A more comprehensive explanation is provided in an earlier draft of this paper and available on request. 
with our observations in figure 5 , here we see that differences in the aggregate dynamics of the lumpy investment versus frictionless model are largely eliminated in general equilibrium. Aggregate investment rates exhibit nearly identical volatility, skewness, and kurtosis across the two model economies. Moreover, there is virtually no difference in persistence, which again is far greater in both models than it was in panel $\mathrm{A}$ and very close to that in the data. This similarity in aggregate investment rate dynamics across the lumpy and frictionless economies extends to other key macroeconomic aggregates, as may be seen in Table 4. There, the variabilities and contemporaneous correlations of aggregate output, employment, consumption and investment indicate that the aggregate business cycle is essentially unaffected by lumpy investment.

Given the differing investment technologies across these models, alongside the marked differences they implied in the partial equilibrium dynamics of section 4.2 , the explanation for the similarities within panel B of Table 3 (as well as those in the histograms of figure 5 and the business cycle moments of table 4) must be traceable to the influence of the representative household that they share in common. Persistence in aggregate investment rates is an immediate result of households' preference for consumption smoothing. The omission of this channel in partial equilibrium places an emphasis on capital adjustment costs in Panel A to generate some of this otherwise absent persistence. In equilibrium, by contrast, adjustment costs are not necessary to smooth aggregate investment demand; this is achieved far more effectively through market-clearing changes in relative prices.

\subsection{Why nonlinearities dissolve}

As discussed above, the nonlinearities generated by lumpy investment in partial equilibrium arise because changes in aggregate productivity are followed by large movements in target capitals that can cause sharp, concurrent changes in the fractions of plants undertaking (unconstrained) capital adjustment. However, such synchronizations in the timing of large investment projects would in turn imply large movements in households' consumption. When we impose market-clearing, this volatility is sharply restrained by procyclical real interest rates, which dampen the changes in target capitals arising from aggregate shocks, and thus dampen changes in adjustment rates. ${ }^{14}$

Recall our earlier example in Figure 2, where we traced our model's responses to a large rise and fall in aggregate productivity. In contrast to the asymmetry there, where aggregate capital rose far more sharply following a 2-standard deviation positive aggregate shock than it fell after the same-sized negative shock, the general equilibrium responses to

\footnotetext{
${ }^{14}$ Procyclical wages further dampen fluctuations in the marginal profits associated with changes in plantlevel capital and thus in target capital stocks.
} 
aggregate shocks are far more symmetric. Following the positive shock, capital now rises by 2.86 percent, while it falls by 2.53 percent with the negative shock. This reflects no greater asymmetry than occurs in the near-linear frictionless model, where capital rises 2.86 percent and falls 2.6 percent in response to the two shocks.

The reason general equilibrium is so effective in eliminating the lumpy investment model's aggregate nonlinearities is that it smooths away much of the movement in target capitals that are essential in generating large changes along the extensive margin. For example, following the positive shock in figure 2, the average target capital stock (weighting the 15 productivity-specific targets by the ergodic distribution over productivities) rose more than 43 percent when our model was solved in partial equilibrium, thereby triggering sufficiently large rightward shifts in the adjustment hazards as to raise the total adjustment rate by 59 percentage points and the aggregate investment rate by 59 percentage points. In general equilibrium, the same shock causes only a 5.1 percent rise in the average target. Because real interest rates rise with an increase in aggregate productivity, plants' incentive to increase capital is mitigated. This restraining force is compounded by accompanying increases in real wages, which both raise the price of current adjustment activities and reduce the benefits of high future capital. As a result, shifts in the adjustment hazards are minimal, leading the aggregate adjustment rate to rise by only 3.6 percentage points and the aggregate investment rate to rise just 2.9 percentage points.

Similarly, following the large negative aggregate shock, the fall in average target capital is 5.5 percent in general equilibrium (versus 40.4 percent in partial equilibrium), yielding only a 3 percentage point fall in the number of adjustors, and a 2.6 percentage point decline in the aggregate investment rate (versus the 20.3 percentage point decline under partial equilibrium). Thus, the rise and fall in the aggregate investment rate following these aggregate shocks is an order of magnitude smaller in equilibrium and almost perfectly symmetric. To appreciate the extent of this symmetry, one need only compare these outcomes with those in the frictionless model. There, through changes in the intensive margin alone, the aggregate investment rate rises by 2.91 percentage points and falls by 2.67 percentage points in response to the two shocks.

\subsection{Summary of aggregate results}

We summarize the primary results of this section as follows. Despite the improved match to microeconomic investment patterns, we find that lumpy plant-level investment has no quantitatively relevant role in the dynamics of aggregate investment. When relative prices are allowed to adjust to clear the markets for labor and goods, large fluctuations in target capital stocks are smoothed dramatically, and thus so are changes in the numbers of 
plants undertaking relatively large capital adjustments. As a result, aggregate nonlinearities associated with lumpy investment disappear, and the dynamics of aggregate investment, labor supply and output are virtually indistinguishable from those in the standard frictionless environment.

In closing, we re-emphasize that the absence of aggregate nonlinearities must not be viewed as a failure of the equilibrium lumpy (or frictionless) model, as these features are not apparent in the aggregate data. With or without capital adjustment costs, our general equilibrium models match the higher moments of aggregate investment rates from the data reasonably well, far more so than the partial equilibrium lumpy model where skewness and kurtosis are sharply overstated. Of course, the empirical improvements associated with the shift to a general equilibrium model are not limited to investment's higher moments. By reducing changes in plants' target capital stocks, market-clearing relative price movements also smooth away the excessively large and abrupt fluctuations in aggregate investment demand we saw in partial equilibrium, so that the resulting investment series matches the empirical persistence and volatility almost perfectly. These results indicate that, irrespective of capital adjustment costs, general equilibrium analysis has an essential role in explaining the dynamics of aggregate investment in actual economies.

\section{Robustness and reconciliation}

While the calibration of most parameters of our lumpy investment model is standard and consistent with the method of Prescott (1986), we have selected the adjustment cost parameters distinguishing this model from its frictionless counterpart, as well as the volatility of plant productivity shocks, to match summary statistics taken from time-averages of the microeconomic investment data. This approach differs sharply from that taken in the recent work of Bachman, Caballero and Engel (2006), and it implies far smaller fixed adjustment costs. These authors choose the size of fixed costs in their single sector model to match the volatility of sectoral investment rates from 3-digit manufacturing data. Defining a group of plants drawing a common sectoral shock as a sector, and assuming sectoral changes do not affect real wages or interest rates, Bachman et. al. require large adjustment costs to smooth sectoral capital reallocation sufficiently to match the variability in the data. This is because plants' outputs are perfectly substitutable in their one sector environment, so there are no sectoral relative prices adjusting in response to changes in economic conditions, thereby dampening investment flows across sectors.

As our equilibrium model does not show evidence of aggregate nonlinearities, while that in Bachman et. al. does, we begin this section by considering whether the disparity in our 
findings may arise from the differing size of our fixed costs, or from our lesser volatility in plant-specific productivities. In row 1 of table 5, we return to the same 10,000 period simulation used in our baseline results, this time reporting the resulting aggregate investment rate moments when the upper support of the fixed cost distribution is raised 10-fold to imply much larger adjustment costs in the model. In the next row, we make these costs even larger, raising the upper support 25-fold, and simultaneously increase the variability of idiosyncratic shocks to 3 times that of the aggregate shock. While these changes do slightly reduce aggregate volatility, the third and fourth moments indicate that they have little effect in generating nonlinearities.

Given that large increases in the size of our fixed adjustment costs and plant-specific productivity variations fail to alter our baseline results, we next consider the second distinguishing feature of our model relative to that examined by Bachman et. al., the incidence of adjustment costs. Our baseline calibration allows for a range of investment rates around zero that are exempt from fixed costs, where the width of this range is taken to match aspects of the average plant distribution. Bachman et. al. allow no such interval; instead, they assume that, if a plant chooses not to pay its fixed cost, it must replace 50 percent of the capital that it would otherwise passively shed through depreciation. In the third row of table 5, we re-examine our model's aggregate results when we modify the interval of investment rates exempted from adjustment costs to allow plants to replace all of their depreciated capital without incurring fixed costs; however, we do not force our plants to undertake this investment. Again, we find negligible changes in the model's aggregate dynamics relative to our baseline results, with no greater evidence of skewness or kurtosis. From this, we conclude that it is not plants' ability to undertake maintenance investment without incurring adjustment costs that explains the nonlinearities uncovered in Bachman et. al. and absent in our results. ${ }^{15}$

In the remainder of this section, we take a different approach toward isolating the sources

\footnotetext{
${ }^{15}$ Motivated by arguments in Gourio and Kashyap (2006), we have also explored cases where adjustment costs are both very large and highly predictable for plants, as well as cases with quite low returns to scale in production, where the overall incidence of fixed costs is magnified by difficulties in concentrating production among few plants. Our aggregate findings appear robust to such changes; in each case, the equilibrium lumpy model exhibits no evidence of nonlinearities. For example, when we assume that fixed costs are drawn from a beta distribution that is sharply right-skewed with most probability concentrated at its upper support ( $\alpha=3$ and $\beta=\frac{1}{3}$ ), and we select the upper support at $\frac{1}{2}$ to imply total output lost to adjustment costs averages 3.5 percent of total investment (as in Gourio and Kashyap (2006)), the resulting third and fourth moments for the model's aggregate investment rate are 0.077 and -0.062 respectively. Continuing to assume the beta distribution, these moments are 0.080 and -0.065 when we simultaneously reduce returns to scale from 0.90 to 0.65 (while lowering $\varphi$ to maintain total hours averaging $\frac{1}{3}$ and raising $\sigma_{\eta_{z}}$ to hold the variability of output in the frictionless model unchanged relative to the baseline results).
} 
of the disparate findings across these two equilibrium lumpy investment studies. We begin by imposing each of the assumptions made by Bachman et. al. to reproduce their aggregate nonlinearities, using essentially their parameter values (with an innocuous adjustment to allow for a balanced growth path). Next, to gauge the importance of each, we remove one assumption at a time so long as evidence of nonlinearities remains. A final assumption that will be important in this exercise is that regarding the representative household's attitude toward risk and consumption smoothing. Across our lumpy investment and frictionless model economies, the representative household has a unit elasticity of intertemporal substitution. While this may be considered somewhat high, it lies within the range of standard values applied in quantitative dynamic stochastic general equilibrium studies. ${ }^{16}$ By contrast, the household in the Bachman et. al. lumpy investment economy is essentially risk-neutral, with this elasticity exceeding 9 . Such preferences imply far greater tolerance for fluctuations in consumption, thus making the household supply of investment goods very flexible and encouraging larger movements in target capital stocks and thus adjustment hazards.

When we combine the large adjustment costs, high variance in plant-level productivity, and mandatory maintenance investment described above together with the near riskneutrality assumption, we obtain the Bachman et. al. nonlinearities in aggregate investment rates; skewness rises from the 0.067 of our model nearly 5 -fold, to 0.315 . After removing the extreme elasticity of intertemporal substitution, instead setting $\sigma=1$, we find that roughly half of this skewness remains, 0.151. Next, we eliminate the assumption that plants must replace one-half of their depreciated capital in any period that they do not pay their fixed costs, instead applying the more traditional assumption that such plants undertake zero investment. ${ }^{17}$ This removes virtually all remaining skewness, despite the large adjustment costs and volatile plant productivity shocks still in place. The result, at 0.071 , is indistinguishable from that in our model. Thus, we find that the aggregate results of Bachman et. al. are reconciled to ours with the removal of the two specific assumptions regarding household preferences and mandatory maintenance. The question of whether nonconvex capital adjustment costs cause aggregate nonlinearities then appears simply a question about the plausibility of these two assumptions.

\footnotetext{
${ }^{16}$ The same value is chosen by Bachman et. al. for the household residing in their frictionless economy.

${ }^{17}$ In a sense, required maintainence investment has the effect of imposing a partial investment irreversibility. Under this assumption, plants experiencing rises in their relative productivity will be reluctant to adopt a high capital stock, as they may be forced to retain much of it in the future until they agree to pay a fixed adjustment cost. This then compresses the steady-state distribution of plants over capital. As a result, any given shift in adjustment hazards will imply greater changes in overall adjustment rates.
} 


\section{Additional Results}

We now turn to examine our model's predictions involving plant-level investment. In this section of additional results, we explore how plants' investments are influenced by the interaction of idiosyncratic shocks, fixed adjustment costs, and equilibrium price movements.

\subsection{Role of general equilibrium in microeconomic dynamics}

Given the large influence of general equilibrium in our findings involving aggregate dynamics, we begin by considering how much information is lost in abstracting from marketclearing price adjustments if our interest lies instead in the dynamics of highly disaggregated series, such as the investments undertaken by individual production units. Naturally, when idiosyncratic productivity shocks give rise to a nontrivial distribution of plants over investment rates, and the effect of these plant-level shocks is large relative to that of the calibrated aggregate shock, the time-averaged cross-sectional distribution is relatively unaffected by equilibrium. Differences in plants' investment rates, on average, represent largely a reallocation of capital from one production unit to another, and such reallocations have no effect on aggregate investment. However, this does not imply that the dynamics of plant-level investment are independent of equilibrium.

The period-by-period distribution of plant investment rates changes over time in response to aggregate shocks. Because the associated movements in relative prices feed back into plant-level decisions, the extent of these changes may be sharply distorted in a partial equilibrium study that omits market-clearing relative price adjustments. For example, when the lumpy investment model is simulated for 10,000 periods under partial equilibrium, the standard deviation of the fraction of the economy's plants exhibiting positive investment spikes in each period is 0.12 , and the standard deviation of the size of these spikes is 0.08 . When the same simulation is undertaken in general equilibrium, each of these standard deviations falls to 0.01 .

We further illustrate this point through the comparison of some simple panel regressions

in Table 6 . In row 1, we regress plant investment rates on changes in aggregate productivity, $\Delta z$, and changes in plant-specific productivity, $\Delta \varepsilon$, using simulated data from our general equilibrium lumpy investment model. In row 2, we repeat this same exercise using data from the lumpy model simulated in partial equilibrium. As expected, the coefficients on $\Delta \varepsilon$ across these two rows are large and essentially identical. However, plant investments are far less responsive to changes in aggregate total factor productivity when the resulting marketclearing price movements are included than they are when these restraints are ignored. The general equilibrium coefficient on $\Delta z$ reflecting plants' investment elasticity to an aggregate 
shock, 0.423 , is exaggerated 13 -fold when real wage and interest rates are not allowed to respond to the change in aggregate conditions.

Because large aggregate shocks are relatively infrequent in our calibrated study, plants' investment rates over long simulations are usually well-predicted by the partial equilibrium model. However, the sharply differing micro-level elasticity to changes in aggregate total factor productivity naturally implies that a given plant will invest quite differently at some times depending on whether or not it faces equilibrium prices. Over those dates when changes in aggregate productivity are large, the errors introduced by ignoring endogenous movements in relative prices will be substantial. From this, we conclude that equilibrium analysis is essential for understanding the dynamics of investment even at the most disaggregated level, most particularly in times of large aggregate disturbances. It may be useful to recall that it is precisely during such times that existing partial equilibrium studies have found substantial differences between lumpy investment models and standard linear models with convex adjustment technologies (see, for example, Caballero, Engel and Haltiwanger (1995) and Caballero and Engel (1999)).

\subsection{Role of nonconvexities in microeconomic investment}

Throughout the lumpy investment literature, it has been maintained that nonconvex capital adjustment costs cause lumpy investments at the plant. A brief comparison of the average plant investment distribution in our model economy relative to that arising in absence of adjustment costs reveals that this is not necessarily true. In fact, if the effect of plant-specific shocks is large relative to aggregate shocks, as consistent with recent estimates, their presence can completely overturn the previously understood role of nonconvex adjustment costs at the plant.

Absent differences in plant-level productivities, the standard model with frictionless investment implies a continuum of identical plants that, on average, undertake modest positive investments in every period to replace their depreciated capital. The introduction of nonconvex capital adjustment costs to this environment necessarily generates the trademark features of lumpy investment, inaction and spikes, since they lead some plants to delay adjustment sufficiently that their capital stocks drift far from that to which they eventually adjust. However, consider instead the frictionless model with idiosyncratic productivity shocks reported in row 1 of Table 7 . Here, before the inclusion of capital adjustment costs, there is already a nontrivial cross-sectional distribution of plant investment rates determined by the distribution of plant-specific productivity shocks. Notice that these volatile idiosyncratic shocks on their own cause both positive and negative investment spikes in the average year; in fact, these observations are overstated relative to the LRD. When fixed adjustment 
costs are added to this environment, moving from row 1 to row 2 , we observe that fixed costs do not cause additional lumpy investments, but instead eliminate some of their occurrences, as indeed is necessary to achieve consistency with the data.

Under frictionless capital adjustment, plants' investments are, on average, extremely responsive to changes in their individual productivities. Through a pure reallocation of aggregate investment, the economy in row 1 exhibits positive investment spikes among plants experiencing large increases in relative productivity, as well as negative spikes among those suffering large decreases in relative productivity. Nothing restrains this reallocation, because it can be costlessly reversed in any subsequent date. However, such reversals are not costless in the economy with capital adjustment frictions. A plant in row 2 realizing raised relative productivity will be more cautious in selecting its new target capital, knowing that, in some nearby date when its productivity may fall, it may at the same time face a high fixed cost to re-adjust its capital to a lowered target. Thus, even if it pays its current fixed cost to adopt a new target, the plant's investment is tempered by an effort to avoid future adjustment costs. A similar restraint applies to negative investment in response to a fall in relative productivity. For this reason, fixed adjustment costs act to reduce the volatility of plant investments, yielding fewer investment spikes.

Beyond eliminating excess spikes, nonconvex costs can take on a secondary role that further reduces the distance between model and actual plant data, but has not been emphasized in previous studies. Comparing the ratio of positive investment (spike) observations to negative investment (spike) observations in row 1 versus row 2, we find that the adjustment costs boost asymmetries in plant-level investment. Recall our explanation above for why these costs eliminate excess spikes. Because depreciation and technological progress automatically erode inactive plants' effective capital stocks, the reduction in a plant's value caused by a high future adjustment cost will be greater if a plant finds itself with too little capital, rather than too much capital. As a result, plants are less cautious in raising their capital stocks than in lowering them, so that the presence of fixed costs increases the fraction of positive investment (spike) observations relative to negative ones.

We emphasize the changed role of nonconvex costs in the presence of idiosyncratic shocks because it is essential that we understand what these costs actually do if we are to establish their importance in explaining establishment-level investment. If their role is to remove investment spikes and cause asymmetry, as we have seen here, then the same effect might be similarly achieved by either investment irreversibilities or by combinations of fixed costs, irreversibilities and convex costs. Thus there may be no aspect of microeconomic behavior that is uniquely explained by the presence of nonconvex adjustment costs. Viewed another way, if idiosyncratic shocks are the primary force explaining plant investment differences, it 
may be virtually impossible to use the establishment investment data to infer the relative size or importance of these costs relative to other frictions.

\section{Concluding Remarks}

We have studied a dynamic stochastic general equilibrium model with nonconvex capital adjustment costs and plant-specific differences in productivity. By introducing persistent plant-level productivity shocks and allowing small investments exempt from adjustment costs, our model reproduces essential empirical regularities involving establishment-level investment. In this environment, equilibrium movements in real interest rates and wages play an essential role in adding persistence to aggregate investment rates, bringing the model closer to the data. An additional consequence of such movements in relative prices is that they eliminate the implications of plant-level nonconvexities for aggregate dynamics. In partial equilibrium, these nonconvexities lead to aggregate nonlinearities through large changes in plants' target capital stocks that drive large changes in the fractions of plants adjusting to these targets. Such nonlinearities disappear in general equilibrium, however, because procyclical movements in real wages and interest rates substantially dampen the changes in plants' target capital stocks that follow an aggregate shock.

Throughout our analysis, we have assumed that output is perfectly substitutable across production units. This makes the reallocation of resources, in response to idiosyncratic shocks, optimal from the perspective of the representative household. Conversely, it also encourages the avoidance of capital adjustment costs through the concentration of investment. If we instead considered an environment where firms produced distinct goods, such disparities in the distribution of inputs would be more costly. This suggests that, for a given distribution of idiosyncratic shocks and capital adjustment costs, more firms would undertake unconstrained capital adjustments in each period. With the average fraction of firms adjusting nearer one, this would move the model with fixed adjustment costs closer to the frictionless environment without these costs. At the same time, it would also dampen the aggregate response to shocks, given a stronger incentive to adjust production evenly across the distribution of firms, and thus larger rises in overall adjustment costs. Thus, we conjecture that such a generalization would move the lumpy investment model to more closely resemble a linear model with convex capital adjustment costs. 


\section{References}

[1] Bachman, R., R. J. Caballero and E. M. R. A. Engel (2006) "Lumpy Investment in Dynamic General Equilibrium," Working Paper, Yale University.

[2] Bertola, G. and R. J. Caballero (1994) "Irreversibility and Aggregate Investment," Review of Economic Studies 61, 223-246.

[3] Caballero, R. J. (1999) "Aggregate Investment," chapter 12 in M. Woodford and J. Taylor (eds.) Handbook of Macroeconomics, vol. IB. Amsterdam: North Holland.

[4] Caballero, R. J and E. M. R. A. Engel (1999) "Explaining Investment Dynamics in U.S. Manufacturing: A Generalized (S, s) Approach," Econometrica 67, 783-826.

[5] Caballero, R. J., E. M. R. A. Engel and J. C. Haltiwanger (1995) "Plant-Level Adjustment and Aggregate Investment Dynamics," Brookings Papers on Economic Activity 2, 1-39.

[6] Chirinko, R. S. (1993), "Business Fixed Investment Spending: Modeling Strategies, Empirical Results, and Policy Implications," Journal of Economic Literature 31, 18751911.

[7] Comin, D. and T. Philippon (2005) "The Rise in Firm-Level Volatility: Causes and Consequences," NBER Working Paper No. 11388.

[8] Cooper, R. W. and J. Ejarque (2001) "Exhuming Q: Market Power vs. Capital Market Imperfections," Working Paper 611, Federal Reserve Bank of Minneapolis.

[9] Cooper, R. W., J. C. Haltiwanger and L. Power (1999) "Machine Replacement and the Business Cycle: Lumps and Bumps," American Economic Review 89, 921-946.

[10] Cooper, R. W. and J. C. Haltiwanger (2002) "On the Nature of Capital Adjustment Costs," University of Texas at Austin working paper.

[11] Cooper, R. W. and J. C. Haltiwanger (2006) "On the Nature of Capital Adjustment Costs," Review of Economic Studies 73, 611-633.

[12] Gourio, F. and A. K. Kashyap (2006) "Investment Spikes: New Facts and a General Equilibrium Exploration," Working Paper, Boston University.

[13] Hansen, G. D. (1985) "Indivisible Labor and the Business Cycle," Journal of Monetary Economics 16, 309-327. 
[14] Khan, A. and J. K. Thomas (2003) "Nonconvex Factor Adjustments in Equilibrium Business Cycle Models: Do Nonlinearities Matter?" Journal of Monetary Economics $50,331-360$.

[15] King, R. G. and S. T. Rebelo (1999) "Resuscitating Real Business Cycles," chapter 14 in M. Woodford and J. Taylor (eds.) Handbook of Macroeconomics, vol. IB. Amsterdam: North-Holland.

[16] Krusell, P. and A.A. Smith Jr., (1997), "Income and Wealth Heterogeneity, Portfolio Choice, and Equilibrium Asset Returns," Macroeconomic Dynamics 1, 387-422.

[17] Prescott, E. C. (1986) "Theory Ahead of Business Cycle Measurement," Federal Reserve Bank of Minneapolis Quarterly Review 10, 9-22.

[18] Rogerson, R. (1988) "Indivisible Labor, Lotteries and Equilibrium," Journal of Monetary Economics 21, 3-16.

[19] Thomas, J. K. (2002) "Is Lumpy Investment Relevant for the Business Cycle?" Journal of Political Economy 110, 508-534.

[20] Thomas, J. K. (2004) “Multivariate Spline Interpolation," E8313 Lecture Notes, University of Minnesota.

[21] Veracierto, M. L. (2002) "Plant-Level Irreversible Investment and Equilibrium Business Cycles," American Economic Review 92, 181-197. 
Figure 1: Distribution of aggregate investment rates in partial equilibrium
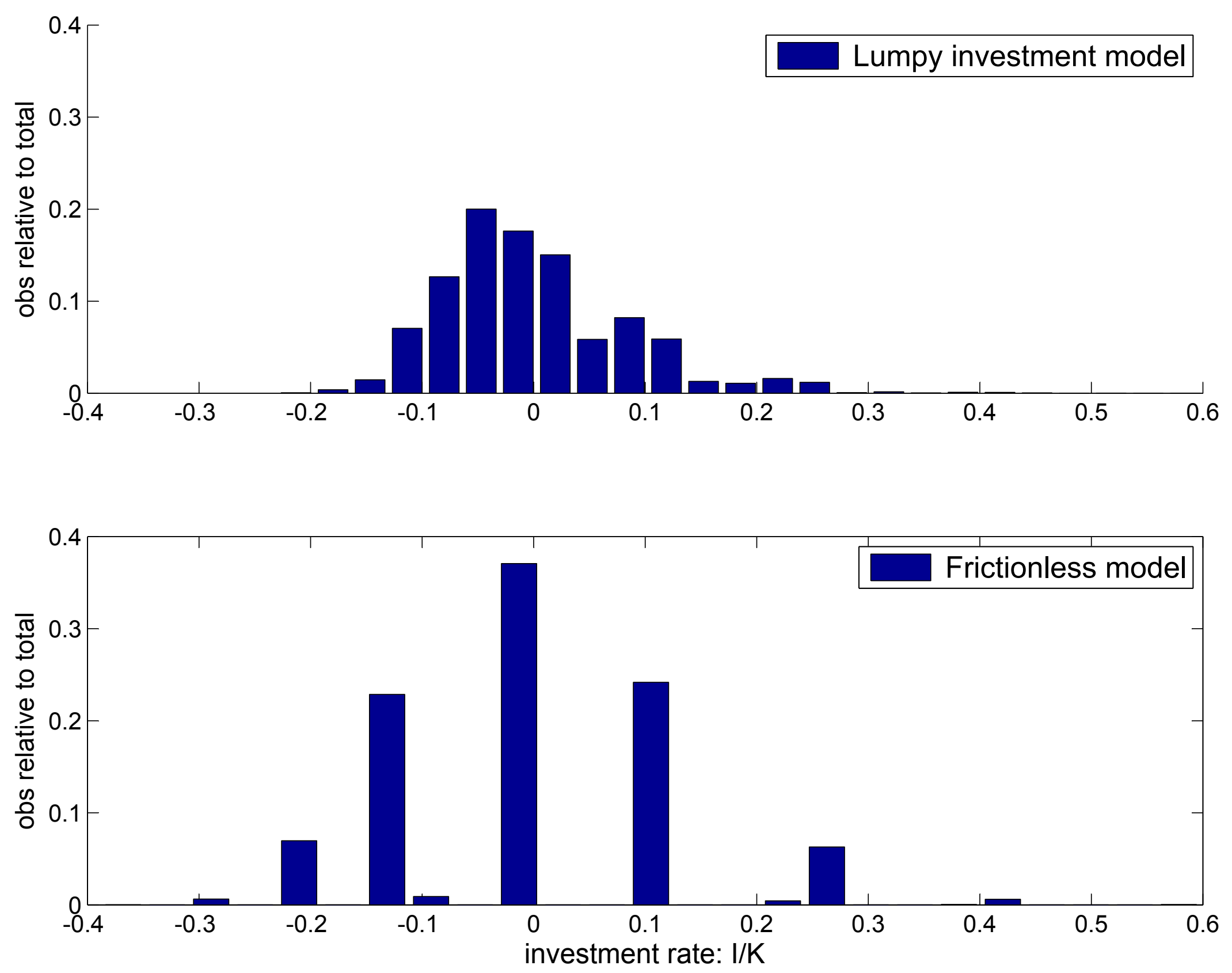
Figure 2: Partial equilibrium aggregate capital responses

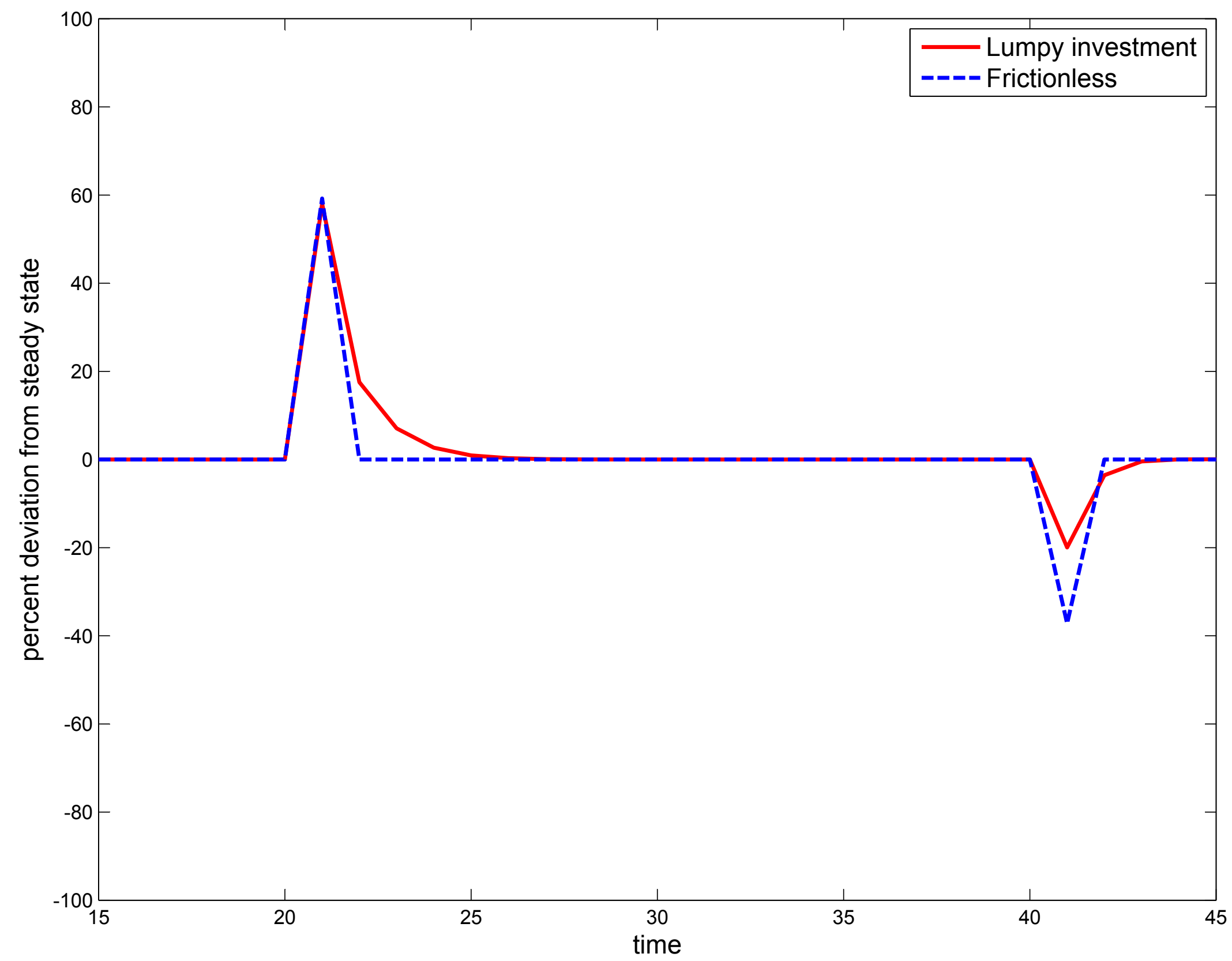


Figure 3: Steady state adjustment in common productivity lumpy model

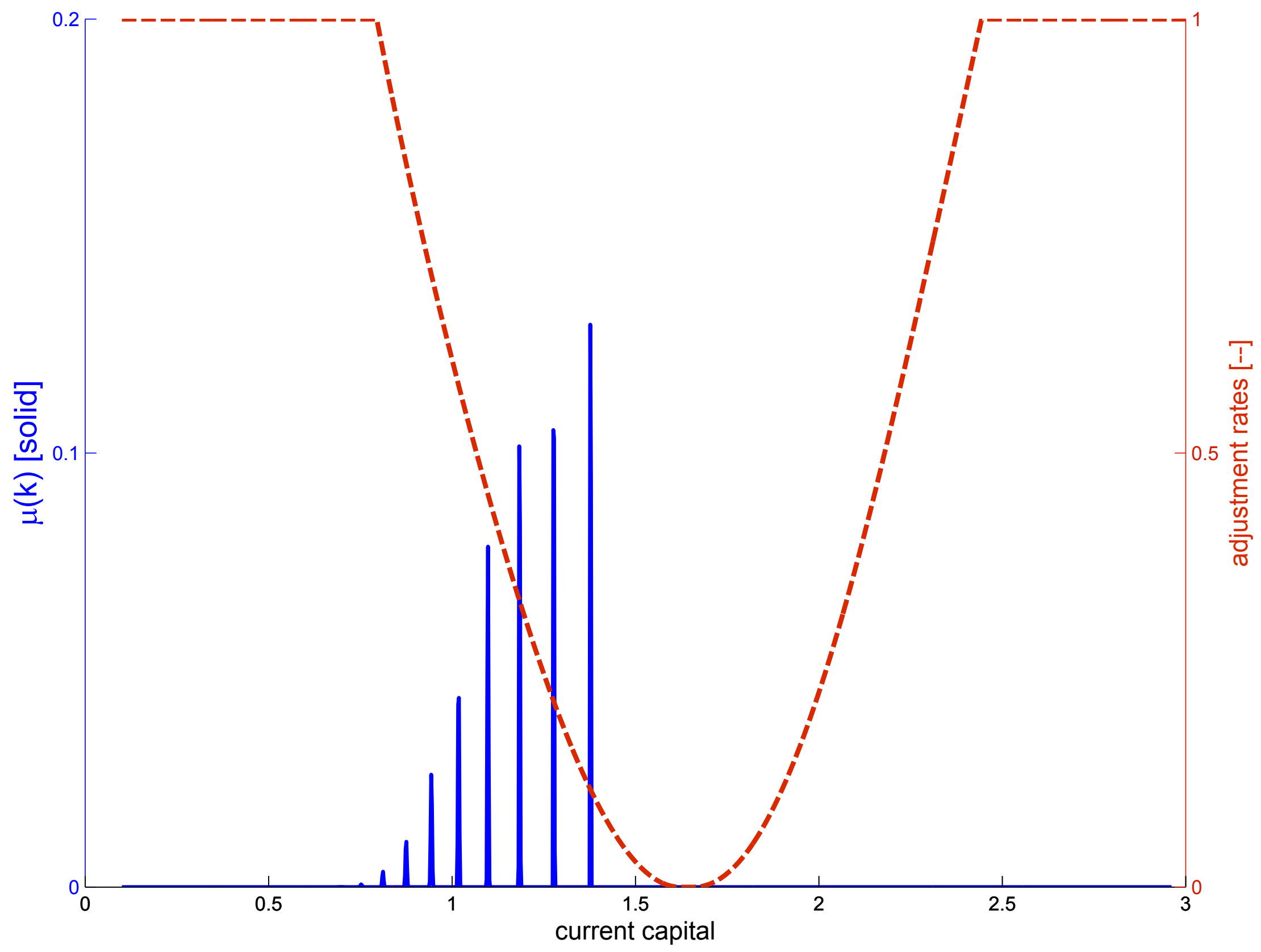


Figure 4: Adjustment responses in the common productivity model
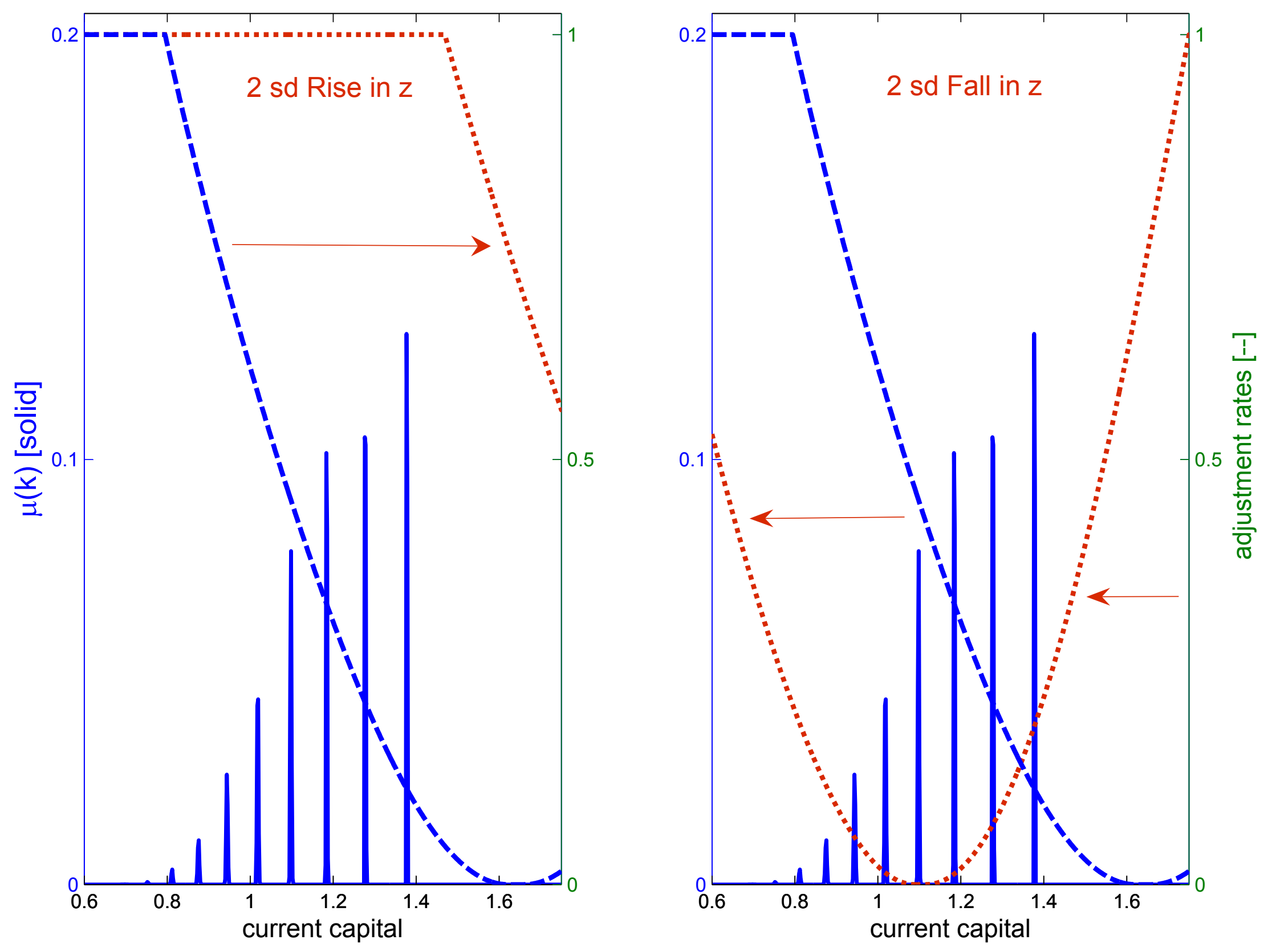
Figure 5: Distribution of aggregate investment rates in general equilibrium
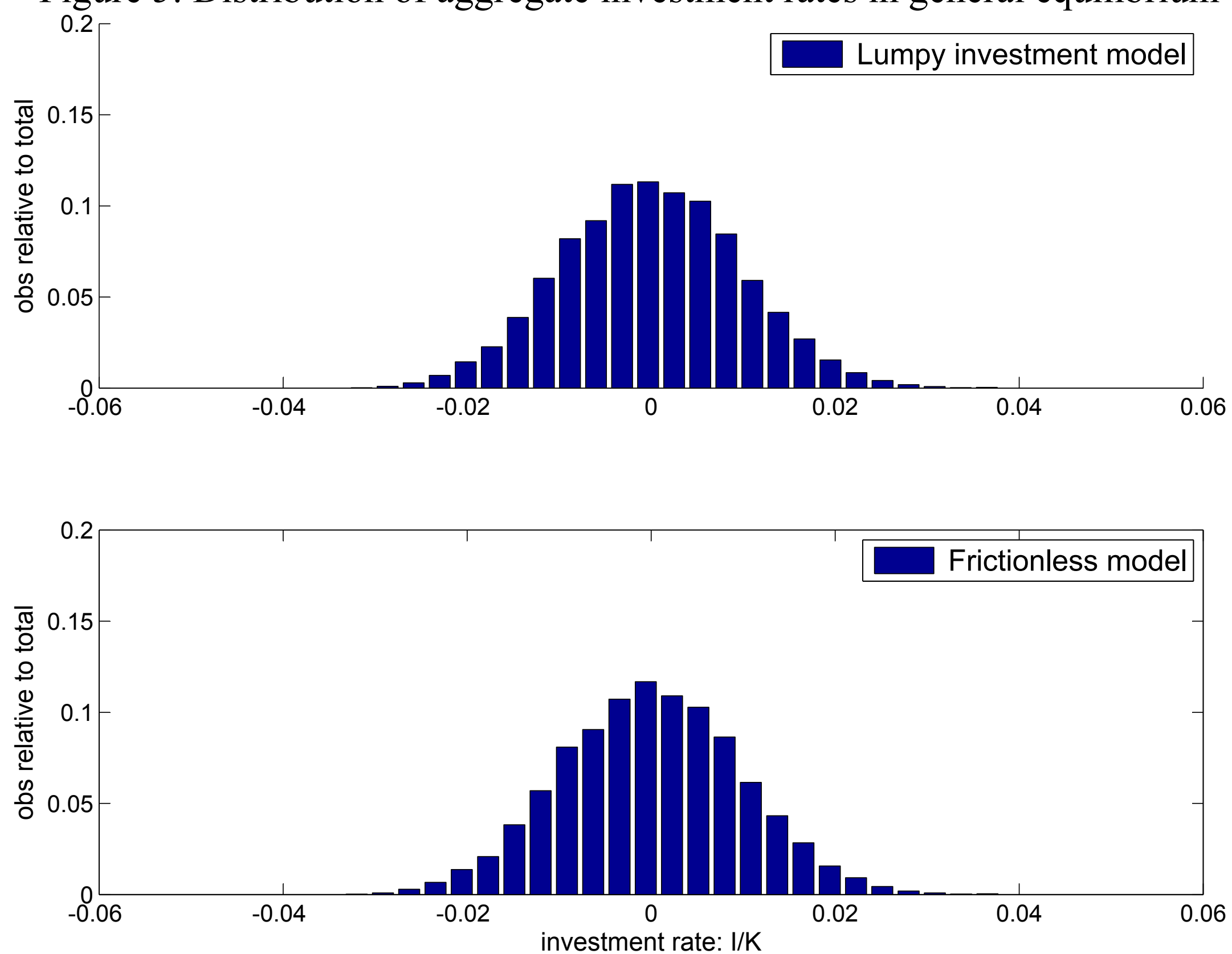
Table 1. Baseline parameter values

\begin{tabular}{cccccccc||cccc}
\hline \hline$\gamma$ & $\beta$ & $\delta$ & $\alpha$ & $v$ & $\varphi$ & $\rho_{\mathrm{z}}$ & $\sigma_{\mathrm{nz}}$ & $\rho_{\varepsilon}$ & $\sigma_{n \varepsilon}$ & $\mathrm{b}$ & $\xi$ \\
\hline 1.016 & 0.977 & 0.069 & 0.256 & 0.640 & 2.400 & 0.859 & 0.014 & 0.859 & 0.022 & 0.011 & 0.0083 \\
\hline \hline
\end{tabular}

Table 2. Matching the time-averaged plant investment data

\begin{tabular}{c|c|c|c|c|c|}
\hline \hline average annual fraction of plants exhibiting: & Inaction & $\begin{array}{c}\text { Positive } \\
\text { Spike }\end{array}$ & $\begin{array}{c}\text { Negative } \\
\text { Spike }\end{array}$ & $\begin{array}{c}\text { Positive } \\
\text { Invest. }\end{array}$ & $\begin{array}{c}\text { Negative } \\
\text { Invest. }\end{array}$ \\
\hline \hline LRD data & 0.081 & 0.186 & 0.018 & 0.815 & 0.104 \\
\hline \hline (1) traditional lumpy & 0.789 & 0.187 & 0.000 & 0.211 & 0.000 \\
\hline (2) extended lumpy with plant-specific TFP & 0.073 & 0.185 & 0.010 & 0.752 & 0.175 \\
\hline \hline
\end{tabular}

DATA: Cooper and Haltiwanger (2005). Traditional model: $\sigma_{\eta \varepsilon}=b=0$, upper support $=0.014$ to fit positive spike obs. 
Table 3. Role of nonconvexities in aggregate investment rate dynamics

\begin{tabular}{|l|c|c|c|c|}
\hline \hline & Persistence & $\begin{array}{c}\text { Standard } \\
\text { Deviation }\end{array}$ & Skewness & Kurtosis \\
\hline \hline \multicolumn{1}{|c|}{ postwar U.S. } & 0.706 & 0.008 & -0.182 & -0.743 \\
\hline \hline \multicolumn{5}{|c|}{ A. partial equilibrium models } \\
\hline \hline (1) PE frictionless & -0.069 & 0.128 & 0.358 & 0.140 \\
\hline (2) PE lumpy investment & 0.210 & 0.085 & 1.121 & 2.313 \\
\hline \hline \multicolumn{5}{|c|}{ B. general equilibrium models } \\
\hline \hline (1) GE frictionless & 0.659 & 0.010 & 0.048 & 0.048 \\
\hline (2) GE lumpy investment & 0.662 & 0.010 & 0.067 & -0.074 \\
\hline \hline
\end{tabular}

DATA: Annual private investment-to-capital ratio, 1954 - 2002, computed using BEA tables. 
Table 4. Aggregate business cycle moments*

\begin{tabular}{|l|c|c|c|c|c|c|}
\hline \hline & $\mathrm{Y}$ & $\mathrm{Z}$ & $\mathrm{N}$ & $\mathrm{C}$ & $\mathrm{I}$ & $\mathrm{K}$ \\
\hline \multicolumn{7}{|c|}{ A. Standard Deviations Relative to Output } \\
\hline (1) GE Frictionless & 2.277 & 0.602 & 0.645 & 0.429 & 3.562 & 0.494 \\
\hline (2) GE Lumpy & 2.264 & 0.605 & 0.639 & 0.433 & 3.539 & 0.492 \\
\hline \multicolumn{7}{|c|}{ B. Contemporaneous Correlations with Output } \\
\hline (1) GE Frictionless & & 1.000 & 0.955 & 0.895 & 0.976 & 0.034 \\
\hline (2) GE Lumpy & & 1.000 & 0.956 & 0.900 & 0.976 & 0.034 \\
\hline
\end{tabular}

* The logarithm of each series is HP-filtered using a weight of 100. The first column of panel A reports percent standard deviations of output. 
Table 5. Robustness

\begin{tabular}{|l|c|c|c|c|}
\hline \hline & Persistence & $\begin{array}{c}\text { Standard } \\
\text { Deviation }\end{array}$ & Skewness & Kurtosis \\
\hline \hline \multicolumn{1}{|c|}{ postwar U.S. } & 0.706 & 0.008 & -0.182 & -0.743 \\
\hline \hline baseline lumpy & 0.662 & 0.010 & 0.067 & -0.074 \\
\hline (1) big fixed costs & 0.677 & 0.009 & 0.071 & -0.066 \\
\hline (2) huge fixed costs and big $\sigma_{\varepsilon}$ & 0.681 & 0.009 & 0.071 & -0.064 \\
\hline (3) no fixed costs for $\mathrm{i} \in[0, \delta \mathrm{k}]$ & 0.665 & 0.010 & 0.070 & -0.057 \\
\hline \hline
\end{tabular}

Table 6. Equilibrium and the dynamics of plant investment rates

\begin{tabular}{|l|c|c|c||c|c|}
\hline \hline $\begin{array}{r}\text { Panel regressions from } \\
\text { simulated lumpy models. } \\
\text { plant } \mathrm{i} / \mathrm{k} \text { on: }\end{array}$ & constant & $\Delta \mathbf{z}$ & $\Delta \varepsilon$ & $\begin{array}{c}\text { adj. } \\
\text { R-squared }\end{array}$ & $\begin{array}{c}\text { S.E. of } \\
\text { regression }\end{array}$ \\
\hline (1) General equilibrium data & 0.107 & $\begin{array}{c}0.423 \\
(0.047)\end{array}$ & $\begin{array}{c}5.126 \\
(0.032)\end{array}$ & 0.227 & 0.215 \\
\hline (2) Partial equilibrium data & 0.112 & $\begin{array}{c}5.464 \\
(0.051)\end{array}$ & $\begin{array}{c}5.414 \\
(0.034)\end{array}$ & 0.289 & 0.233 \\
\hline \hline
\end{tabular}


Table 7. Role of fixed costs in plant-level investments

\begin{tabular}{|l|c|c|c|c|c|}
\hline \hline $\begin{array}{c}\text { average annual fraction } \\
\text { of plants exhibiting: }\end{array}$ & Inaction & $\begin{array}{c}\text { Positive } \\
\text { Spike }\end{array}$ & $\begin{array}{c}\text { Negative } \\
\text { Spike }\end{array}$ & $\begin{array}{c}\text { Positive } \\
\text { Invest. }\end{array}$ & $\begin{array}{c}\text { Negative } \\
\text { Invest. }\end{array}$ \\
\hline \multicolumn{1}{|c|}{ LRD data } & 0.081 & 0.186 & 0.018 & 0.815 & 0.104 \\
\hline (1) frictionless model & 0.032 & 0.204 & 0.028 & 0.611 & 0.356 \\
\hline (2) lumpy investment model & 0.073 & 0.185 & 0.010 & 0.752 & 0.175 \\
\hline \hline
\end{tabular}




\section{Appendices}

\section{A Numerical method}

Solving the frictionless model is fairly straightforward, even in the presence of persistent plant-level shocks. Despite a distribution of plants over capital and productivities, the endogenous aggregate state vector may be characterized by total capital and a timeinvariant distribution of plants' shares of the aggregate capital stock that are functions of their idiosyncratic productivity levels (as shown in section B). Given the invariance in this distribution of relative capital, the aggregate state vector contains only two time-varying elements, total capital and aggregate productivity, and standard methods may be used to solve the model. The one novelty in our approach is that we apply a nonlinear solution method using piecewise polynomial cubic spline interpolation of the planner's value function. This method is described briefly in Khan and Thomas (2003) and, in more detail, in Thomas (2004). In partial equilibrium, the same nonlinear approach is applied to solving plants' value functions for the lumpy investment models. Note that uncertainty in adjustment costs implies that value functions are smooth objects.

In contrast to its frictionless counterpart, the equilibrium lumpy investment model's aggregate state vector involves a nontrivial distribution of plants, which makes the computation of equilibrium more challenging. Our solution algorithm involves repeated application of the contraction mapping implied by (8) - (10) to solve for plants' start-of-period value functions $V^{0}$, given the price functions $p(z, \mu)$ and $\omega(z, \mu)$ and the laws of motion implied by $\Gamma(z, \mu),\left(\pi_{i j}\right)$ and $\left(\pi_{l m}^{\varepsilon}\right)$. This recursive approach is complicated in two ways. First, recalling that a primary focus throughout this literature has been on lumpy investment's potential for generating aggregate nonlinearities, we must use a solution method that does not rule them out. Moreover, we must adopt a non-local method, because plants' $(S, s)$ decision rules can sometimes hit corners (when interior values for their threshold costs shift to the boundaries of the cost distribution). As explained below, this implies that the number of capital stocks with a positive measure of plants changes over time.

The upper bound on the distribution of capital adjustment costs implies that all plants adjust in finite time; in this sense, the economy has finite memory. Thus, at each idiosyncratic productivity level, the distribution of plants over capital may be described using a finite vector of capital levels and the associated number of plants holding each such level. At the same time, while not high-dimensional, the distribution $\mu$ in the aggregate state vector is still a large object. Even in the lumpy investment model without idiosyncratic productivity 
shocks, it involves 62 variables. The nonlinear solution method predicated by our focus on aggregate nonlinearities makes this numerically intractable, so we use selected moments as a proxy for the distribution in the aggregate state vector.

More specifically, our solution adapts the method of Khan and Thomas (2003) to allow for a two-dimensional distribution of plants over capital and idiosyncratic productivity. Thus, we assume that agents use a smaller object in proxy for the distribution as they forecast the future state to make decisions given current prices. In choosing this proxy, we apply a variation on the method of Krusell and Smith (1997), assuming that agents approximate the distribution in the aggregate state vector with a vector of moments, $m=\left(m_{1}, \ldots, m_{I}\right)$, drawn from the true distribution. Because our work involves discrete choices among producers, we find that using the conditional means from $I$ equal-sized partitions of the distribution is efficient, implying small forecasting errors.

Our solution algorithm iterates between an inner loop and an outer loop, as in Krusell and Smith (1997). In the inner loop, agents' value functions are solved based upon a given set of forecasting rules. Given these value functions, the economy is simulated in the outer loop, where $p$ is endogenously determined in each date. Throughout our simulations, we use the actual distribution of plants over capital and productivity in each period, alongside plants' value functions (derived using the forecasting rules described above), to determine equilibrium prices and quantities, and thus the subsequent period's distribution. Next, the resulting simulation data are used to update the forecasting rules, with which we return to the inner loop, this two-step process continuing until the forecasting rules converge.

Table A1 presents agents' forecasting rules for the common productivity model. In determining their current decisions, agents forecast the future proxy state, $m_{1}^{\prime}$, assumed to be the logarithm of the first moment of the distribution of plants over capital, using the logarithm of the mean of the current distribution, $m_{1}$ (and current aggregate productivity). Similarly, when solving for agents' value functions, we have them assume that the valuation of current output, $p$, is a log-linear function of this mean. Note that adjusted R-squareds are very high, and standard errors are small; almost all the true variation in the mean of the distribution, and in the relative price of output, may be anticipated using these simple forecasting rules.

In the full lumpy investment model, there is a two-dimensional distribution of plants over capital and idiosyncratic productivity. Here, the 15-point discretization of the persistent plant productivity process implies an aggregate state vector where 2029 levels of capital have positive mass. Nonetheless, we find that the solution method described above is robust to this additional source of heterogeneity. The equilibrium forecasting rules are presented in Table A2. Note that there is no loss of accuracy in the forecasting rules with the introduction 
of persistent differences in plant-specific productivity, though we continue to use only the unconditional mean of the distribution of capital as a proxy for the aggregate endogenous state. This suggests that our general equilibrium solution method may be applied to a broad class of models currently studied in partial equilibrium.

\section{B A characterization of the frictionless model}

In this appendix, we derive several analytical results for the full frictionless model characterized by persistent plant-specific total factor productivity shocks and no nonconvex costs of capital adjustment. In lemma 1, under the assumption of Cobb-Douglas production, we establish that the plant decision rule for next period's capital stock may be expressed as the product of two functions whose arguments are the current plant-specific productivity term and the aggregate state, respectively. Thus, in the absence of capital adjustment costs, a plant's decision rule for future capital is independent of its current capital. Moreover, this decision rule is separable in plant-level and aggregate variables.

It is then immediate that, given any initial distribution of plants, future distributions involve only $N_{\varepsilon}$ time-varying values of capital with positive mass. The separability of plants' capital stock decision rules into a plant-specific and an aggregate component implies that the shares of the aggregate capital stock across plant types are time-invariant. In other words, the distribution of capital across plants, once normalized, satisfies a time-invariance property. This property ensures that, in any period, the entire distribution of capital, and thus production, may be described using a time-invariant share distribution and the aggregate capital stock, as established in lemma 2. As a result, the aggregate capital stock is sufficient to fully characterize variation in the endogenous state vector of the full version of the frictionless model, just as under common productivity. Moreover, it follows that all aggregate dynamics of the full model may be recovered using a representative firm approach, although for brevity we omit the details here.

We begin our analysis of the frictionless model by describing the problem of a plant. In the absence of capital adjustment costs, the value of any plant of type $\left(\varepsilon_{l}, k\right)$ will solve the following functional equation:

$$
\begin{aligned}
v^{1}\left(\varepsilon_{l}, k ; z_{i}, \mu\right)= & \max _{n, k^{\prime}}\left[z_{i} \varepsilon_{l} F(k, n)-\omega\left(z_{i}, \mu\right) n-\gamma k^{\prime}+(1-\delta) k\right. \\
& \left.+\sum_{j=1}^{N_{z}} \pi_{i j} d_{j}\left(z_{i}, \mu\right) \sum_{m=1}^{N_{\varepsilon}} \pi_{l m}^{\varepsilon} v^{1}\left(\varepsilon_{m}, k^{\prime} ; z_{j}, \mu^{\prime}\right)\right],
\end{aligned}
$$


subject to $\mu^{\prime}=\Gamma\left(z_{i}, \mu\right)$. Let $N\left(\varepsilon_{l}, k ; z_{i}, \mu\right)$ describe the plant's employment choice and $K\left(\varepsilon_{l}, k ; z_{i}, \mu\right)$ its decision rule for next period's capital stock. The description of households in section 2.2 of the text is unchanged.

A recursive competitive equilibrium is a set of functions

$$
\left(\omega,\left(d_{j}\right)_{j=1}^{N_{z}}, \rho_{1}, \rho_{0}, v^{1}, N, K, W, C, N^{h}, \Lambda^{h}, \Gamma\right)
$$

such that plants and households maximize their expected values and the markets for assets, labor and output clear:

1. $v^{1}$ satisfies $(18)$ and $(N, K)$ are the associated policy functions for plants.

2. $W$ satisfies (5) and $\left(C, N^{h}, \Lambda^{h}\right)$ are the associated policy functions for households.

3. $\Lambda^{h}\left(\varepsilon_{m}, k^{\prime}, \mu ; z, \mu\right)=\mu^{\prime}\left(\varepsilon_{m}, k^{\prime}\right)$, for each $\left(\varepsilon_{m}, k^{\prime}\right) \in \mathbf{S}$.

4. $N^{h}(\mu ; z, \mu)=\int_{\mathbf{S}} N(\varepsilon, k ; z, \mu) \mu(d[\varepsilon \times k])$.

5. $C(\mu ; z, \mu)=\int_{\mathbf{S}}(z \varepsilon F(k, N(\varepsilon, k ; z, \mu))-\gamma K(\varepsilon, k, \xi ; z, \mu)+(1-\delta) k) \mu(d[\varepsilon \times k])$.

6. $\mu^{\prime}\left(\varepsilon_{m}, B\right)=\int_{\left\{\left(\varepsilon_{l}, k\right) \mid K\left(\varepsilon_{l}, k ; z, \mu\right) \in B\right\}} \pi_{l m}^{\varepsilon} \mu\left(d\left[\varepsilon_{l} \times k\right]\right)$, for all $\left(\varepsilon_{m}, B\right) \in \mathcal{S}$, defines $\Gamma$.

\section{B.1 Plant's capital decision rule}

Let $\alpha \in(0,1)$ represent capital's share of production and $\nu \in(0,1)$ be labor's share, where $\alpha+\nu<1$. The choice of employment, $n$, solves $\max _{n}\left(s k^{\alpha} n^{\nu}-\omega n\right)$, where $s=z \varepsilon$ and $\omega$ is the real wage. This yields the employment decision rule $n=\left(\frac{\nu s k^{\alpha}}{\omega}\right)^{\frac{1}{1-\nu}}$, allowing us to express production as $y=s^{\frac{1}{1-\nu}} k^{\frac{\alpha}{1-\nu}}\left(\frac{\nu}{\omega}\right)^{\frac{\nu}{1-\nu}}$. Production net of labor costs is then given by the following:

$$
y-\omega n=(1-\nu) s^{\frac{1}{1-\nu}} k^{\frac{\alpha}{1-\nu}}\left(\frac{\nu}{\omega}\right)^{\frac{\nu}{1-\nu}} .
$$

Substituting (19) into (18), we remove the static employment decision:

$$
\begin{aligned}
v^{1}\left(\varepsilon_{l}, k ; z_{i}, \mu\right)= & \max _{k^{\prime}}\left[(1-\nu)\left[z_{i} \varepsilon_{l}\right]^{\frac{1}{1-\nu}} k^{\frac{\alpha}{1-\nu}}\left(\frac{\nu}{\omega\left(z_{i}, \mu\right)}\right)^{\frac{\nu}{1-\nu}}\right. \\
& \left.\left.-\gamma k^{\prime}+(1-\delta) k\right)+\sum_{j=1}^{N_{z}} \pi_{i j} d_{j}\left(z_{i}, \mu\right) \sum_{m=1}^{N_{\varepsilon}} \pi_{l m}^{\varepsilon} v^{1}\left(\varepsilon_{m}, k^{\prime} ; z_{j}, \mu^{\prime}\right)\right] .
\end{aligned}
$$

The first-order condition is

$$
-\gamma+\sum_{j=1}^{N_{z}} \pi_{i j} d_{j}\left(z_{i}, \mu\right) \sum_{m=1}^{N_{\varepsilon}} \pi_{l m}^{\varepsilon} D_{2} v^{1}\left(\varepsilon_{m}, k^{\prime} ; z_{j}, \mu^{\prime}\right)=0
$$


Combining this with the Benveniste-Scheinkman condition below,

$$
D_{2} v^{1}\left(\varepsilon_{l}, k ; z_{i}, \mu\right)=\alpha\left[z_{i} \varepsilon_{l}\right]^{\frac{1}{1-\nu}} k^{\frac{\alpha}{1-\nu}-1}\left(\frac{\nu}{\omega\left(z_{i}, \mu\right)}\right)^{\frac{\nu}{1-\nu}}+(1-\delta),
$$

we have a stochastic Euler equation for capital:

$$
\gamma=\sum_{j=1}^{N_{z}} \pi_{i j} d_{j}\left(z_{i}, \mu\right) \sum_{m=1}^{N_{\varepsilon}} \pi_{l m}^{\varepsilon}\left(\alpha\left[z_{j} \varepsilon_{m}\right]^{\frac{1}{1-\nu}}\left(k^{\prime}\right)^{\frac{\alpha}{1-\nu}-1}\left(\frac{\nu}{\omega\left(z_{j}, \mu^{\prime}\right)}\right)^{\frac{\nu}{1-\nu}}+(1-\delta)\right) .
$$

Define the following terms:

$$
\begin{aligned}
L_{0}\left(\varepsilon_{l}\right) & =\left(\sum_{m=1}^{N_{\varepsilon}} \pi_{l m}^{\varepsilon}\left(\varepsilon_{m}\right)^{\frac{1}{1-\nu}}\right)^{\frac{1-\nu}{1-(\alpha+\nu)}} \\
L_{1}\left(z_{i}, \mu\right) & =\left(\frac{\gamma-(1-\delta) \sum_{j=1}^{N_{z}} \pi_{i j} d_{j}\left(z_{i}, \mu\right)}{\alpha \sum_{j=1}^{N_{z}} \pi_{i j} d_{j}\left(z_{i}, \mu\right) z_{j}^{\frac{1}{1-\nu}}\left(\frac{\nu}{\omega\left(z_{j}, \mu^{\prime}\right)}\right)^{\frac{\nu}{1-\nu}}}\right)^{\frac{1-\nu}{\alpha+\nu-1}} .
\end{aligned}
$$

Simplification of (21) and use of the definitions in equations (22) - (23) proves the following.

Lemma 1 The capital decision rule for a plant, $K\left(\varepsilon_{l}, k ; z_{i}, \mu\right)$, is independent of $k$ and takes the form $L_{0}\left(\varepsilon_{l}\right) L_{1}\left(z_{i}, \mu\right)$.

\section{B.2 Aggregation}

The fact that plants' future capital stocks are independent of their current capital stocks is central to our aggregation result. This result is not shared by the lumpy investment model because of the inaction arising from its fixed adjustment costs.

We next exploit the implication from lemma 1 that the ratio of capital across any two plants depends only on their lagged productivity levels to describe how the dynamics of this economy may be solved as a standard optimal growth model, with the aggregate state vector effectively reduced to simply the aggregate capital stock and exogenous productivity.

Let $H=\left(h_{1}, \ldots, h_{N_{\varepsilon}}\right)^{T}$ be the vector representing the time-invariant distribution of plants over idiosyncratic shock values solving

$$
H=\left|\begin{array}{cccc}
\pi_{1,1}^{\varepsilon} & \pi_{1,2}^{\varepsilon} & \cdots & \pi_{1, N_{\varepsilon}}^{\varepsilon} \\
\pi_{2,1}^{\varepsilon} & \pi_{2,2}^{\varepsilon} & \cdots & \pi_{2, N_{\varepsilon}}^{\varepsilon} \\
\vdots & \vdots & & \vdots \\
\pi_{N_{\varepsilon}, 1}^{\varepsilon} & \pi_{N_{\varepsilon}, 2}^{\varepsilon} & \cdots & \pi_{N_{\varepsilon}, N_{\varepsilon}}^{\varepsilon}
\end{array}\right| H
$$

Since capital decision rules are independent of current capital, it follows that all plants with the same current idiosyncratic shock value, $\varepsilon_{l}$, will choose the same capital stock for 
next period, $k_{l}=L_{0}\left(\varepsilon_{l}\right) L_{1}\left(z_{i}, \mu\right), l=1, \ldots, N_{\varepsilon}$. Thus, there will be $N_{\varepsilon}$ capital values with positive mass next period, and $h_{l}$ plants, all currently having the idiosyncratic shock value $\varepsilon_{l}$, will begin the next period with $k_{l}$. Define the mean of this distribution of capital $K^{\prime}=\sum_{l=1}^{N_{\varepsilon}} h_{l} k_{l}^{\prime}$. Using lemma 1 , we know

$$
K^{\prime}=\sum_{l=1}^{N_{\varepsilon}} h_{l} L_{0}\left(\varepsilon_{l}\right) L_{1}\left(z_{i}, \mu\right) .
$$

Toward establishing a time-invariant relative distribution of plants over capital, it is useful to define the following share terms:

$$
\chi_{m} \equiv \frac{L_{0}\left(\varepsilon_{m}\right)}{\sum_{l=1}^{N_{\varepsilon}} h_{l} L_{0}\left(\varepsilon_{l}\right)}, m=1, \ldots, N_{\varepsilon}
$$

Define the vector of these share terms as $\chi \equiv\left(\chi_{1}, \ldots, \chi_{N_{\varepsilon}}\right)$.

While all plants with the same current idiosyncratic shock value will choose a common capital stock for next period, their subsequent idiosyncratic productivities will differ. Let $\widetilde{H}$ describe the two-dimensional distribution of plants over $\varepsilon_{t-1}$ and $\varepsilon_{t}$. An element of this $N_{\varepsilon} \times N_{\varepsilon}$ matrix, $\widetilde{h}_{l m}$, represents the number of plants that had $\varepsilon_{t-1}=\varepsilon_{l}$ and have $\varepsilon_{t}=\varepsilon_{m}$ :

$$
\widetilde{h}_{l, m}=\pi_{l, m} h_{l}, \quad \text { for } l=1, \ldots, N_{\varepsilon} \text { and } m=1, \ldots, N_{\varepsilon} .
$$

In any period $t+1$, where $t \geq 0$, the distribution of plants is then completely characterized by $\widetilde{H}$ and $\chi$ together with the aggregate capital stock, $K_{t+1}$. This establishes lemma 2 below.

Lemma 2 Let $K$ be the aggregate capital stock, and define $k_{l} \equiv \chi_{l} K, l=1, \ldots, N_{\varepsilon}$. For each $\varepsilon_{m}, m=1, \ldots, N_{\varepsilon}, \mu\left(\varepsilon_{m}, k_{l}\right)=\widetilde{h}_{l, m} \geq 0$, and elsewhere $\mu=0$.

Thus, the distribution of plants over both idiosyncratic productivity levels and capital stocks has $N_{\varepsilon}^{2}$ elements in all. More importantly, this distribution is completely characterized by two time-invariant objects, $\widetilde{H}$ and $\chi$, and the aggregate capital stock. It follows, then, that the aggregate state vector of the full frictionless model has only two time-varying elements, aggregate capital and exogenous aggregate productivity. 
Table A1. Forecasting rules in common productivity lumpy model

\begin{tabular}{|cc|c|c|c|c|}
\cline { 3 - 6 } \multicolumn{1}{c}{} & $\beta_{1}$ & $\beta_{2}$ & S.E. & $\mathrm{R}^{2}$ \\
\hline $\mathrm{z}_{1}$ & $\mathrm{~m}_{1}{ }^{\prime}$ & 0.006 & 0.802 & $0.20 \mathrm{e}-3$ & 0.9999 \\
$(119$ obs. $)$ & $\mathrm{p}$ & 0.998 & -0.395 & $0.14 \mathrm{e}-3$ & 0.9999 \\
\hline \hline $\mathrm{z}_{2}$ & $\mathrm{~m}_{1}{ }^{\prime}$ & 0.014 & 0.800 & $0.25 \mathrm{e}-3$ & 0.9999 \\
$(298$ obs. $)$ & $\mathrm{p}$ & 0.990 & -0.393 & $0.15 \mathrm{e}-3$ & 0.9999 \\
\hline \hline $\mathrm{z}_{3}$ & $\mathrm{~m}_{1}{ }^{\prime}$ & 0.021 & 0.798 & $0.25 \mathrm{e}-3$ & 0.9999 \\
$(734$ obs. $)$ & $\mathrm{p}$ & 0.981 & -0.392 & $0.14 \mathrm{e}-3$ & 0.9999 \\
\hline \hline $\mathrm{z}_{4}$ & $\mathrm{~m}_{1}{ }^{\prime}$ & 0.028 & 0.797 & $0.28 \mathrm{e}-3$ & 0.9999 \\
$(1208$ obs. $)$ & $\mathrm{p}$ & 0.972 & -0.392 & $0.15 \mathrm{e}-3$ & 0.9999 \\
\hline \hline $\mathrm{z}_{5}$ & $\mathrm{~m}_{1}{ }^{\prime}$ & 0.035 & 0.796 & $0.31 \mathrm{e}-3$ & 0.9999 \\
$(1682$ obs. $)$ & $\mathrm{p}$ & 0.963 & -0.391 & $0.15 \mathrm{e}-3$ & 0.9999 \\
\hline \hline $\mathrm{z}_{6}$ & $\mathrm{~m}_{1}{ }^{\prime}$ & 0.041 & 0.796 & $0.31 \mathrm{e}-3$ & 0.9999 \\
$(1871$ obs. $)$ & $\mathrm{p}$ & 0.953 & -0.389 & $0.15 \mathrm{e}-3$ & 0.9999 \\
\hline \hline $\mathrm{z}_{7}$ & $\mathrm{~m}_{1}{ }^{\prime}$ & 0.048 & 0.795 & $0.29 \mathrm{e}-3$ & 0.9999 \\
$(1706$ obs. $)$ & $\mathrm{p}$ & 0.944 & -0.388 & $0.14 \mathrm{e}-3$ & 0.9999 \\
\hline \hline $\mathrm{z}_{8}$ & $\mathrm{~m}_{1}{ }^{\prime}$ & 0.055 & 0.794 & $0.26 \mathrm{e}-3$ & 0.9999 \\
$(1237$ obs. $)$ & $\mathrm{p}$ & 0.935 & -0.386 & $0.13 \mathrm{e}-3$ & 0.9999 \\
\hline \hline $\mathrm{z}_{9}$ & $\mathrm{~m}_{1}{ }^{\prime}$ & 0.062 & 0.793 & $0.24 \mathrm{e}-3$ & 0.9999 \\
$(751$ obs. $)$ & $\mathrm{p}$ & 0.926 & -0.386 & $0.11 \mathrm{e}-3$ & 0.9999 \\
\hline \hline $\mathrm{z}_{10}$ & $\mathrm{~m}_{1}{ }^{\prime}$ & 0.070 & 0.791 & $0.26 \mathrm{e}-3$ & 0.9999 \\
$(295$ obs. $)$ & $\mathrm{p}$ & 0.917 & -0.385 & $0.11 \mathrm{e}-3$ & 0.9999 \\
\hline \hline $\mathrm{z}_{11}$ & $\mathrm{~m}_{1}{ }^{\prime}$ & 0.078 & 0.789 & $0.21 \mathrm{e}-3$ & 0.9999 \\
$(99$ obs. $)$ & $\mathrm{p}$ & 0.908 & -0.384 & $0.11 \mathrm{e}-3$ & 0.9999 \\
\hline
\end{tabular}

NOTE. - Forecasting rules are conditional on current productivity, $\mathrm{z}_{\mathrm{i}}$. Each regression takes the form: $\log (y)=\beta_{1}+\beta_{2} \log \left(m_{1}\right)$, where $y=m_{1}$, or $p$. 
Table A2. Forecasting rules in full lumpy model

\begin{tabular}{|c|c|c|c|c|c|}
\hline & & $\beta_{1}$ & $\beta_{2}$ & S.E. & $\mathrm{R}^{2}$ \\
\hline \multirow{2}{*}{$\begin{array}{c}z_{1} \\
\text { (119 obs.) }\end{array}$} & $\mathrm{m}_{1}^{\prime}$ & 0.009 & 0.800 & 0.15 e- 3 & 1.0000 \\
\hline & $\mathrm{p}$ & 0.994 & -0.397 & 0.03 e- 3 & 1.0000 \\
\hline \multirow{2}{*}{$\begin{array}{c}\mathrm{z}_{2} \\
\text { (298 obs.) } \\
\end{array}$} & $\mathrm{m}_{1}^{\prime}$ & 0.016 & 0.798 & $0.22 \mathrm{e}-3$ & 0.9999 \\
\hline & $\mathrm{p}$ & 0.986 & -0.395 & 0.04 e-3 & 1.0000 \\
\hline \multirow{2}{*}{$\begin{array}{c}z_{3} \\
(734 \text { obs.) }\end{array}$} & $\mathrm{m}_{1}{ }^{\prime}$ & 0.023 & 0.796 & 0.23 e- 3 & 0.9999 \\
\hline & $\mathrm{p}$ & 0.977 & -0.394 & 0.04 e- 3 & 1.0000 \\
\hline \multirow{2}{*}{$\begin{array}{c}\mathrm{Z}_{4} \\
\text { (1208 obs.) } \\
\end{array}$} & $\mathrm{m}_{1}^{\prime}$ & 0.030 & 0.795 & $0.26 \mathrm{e}-3$ & 0.9999 \\
\hline & $\mathrm{p}$ & 0.968 & -0.393 & 0.05 e- 3 & 1.0000 \\
\hline \multirow{2}{*}{$\begin{array}{c}\mathrm{z}_{5} \\
\text { (1682 obs.) } \\
\end{array}$} & $\mathrm{m}_{1}^{\prime}$ & 0.037 & 0.794 & 0.27 e- 3 & 0.9999 \\
\hline & $\mathrm{p}$ & 0.958 & -0.392 & 0.05 e- 3 & 1.0000 \\
\hline \multirow{2}{*}{$\begin{array}{c}\mathrm{Z}_{6} \\
\text { (1871 obs.) }\end{array}$} & $\mathrm{m}_{1}{ }^{\prime}$ & 0.044 & 0.079 & 0.28 e- 3 & 0.9999 \\
\hline & $\mathrm{p}$ & 0.949 & -0.391 & 0.05 e- 3 & 1.0000 \\
\hline \multirow{2}{*}{$\begin{array}{c}\mathrm{z}_{7} \\
\text { (1706 obs.) } \\
\end{array}$} & $\mathrm{m}_{1}^{\prime}$ & 0.051 & 0.793 & 0.26 e- 3 & 0.9999 \\
\hline & $\mathrm{p}$ & 0.940 & -0.389 & $0.05 \mathrm{e}-3$ & 1.0000 \\
\hline \multirow{2}{*}{$\begin{array}{c}\mathrm{Z}_{8} \\
\text { (1237 obs.) } \\
\end{array}$} & $\mathrm{m}_{1}{ }^{\prime}$ & 0.058 & 0.792 & 0.24 e- 3 & 0.9999 \\
\hline & $\mathrm{p}$ & 0.931 & -0.388 & $0.05 \mathrm{e}-3$ & 1.0000 \\
\hline \multirow{2}{*}{$\begin{array}{c}\mathrm{Z}_{9} \\
\text { (751 obs.) } \\
\end{array}$} & $\mathrm{m}_{1}^{\prime}$ & 0.065 & 0.792 & 0.23 e- 3 & 0.9999 \\
\hline & $\mathrm{p}$ & 0.921 & -0.386 & 0.04 e- 3 & 1.0000 \\
\hline \multirow{2}{*}{$\begin{array}{c}\mathrm{z}_{10} \\
\text { (295 obs.) } \\
\end{array}$} & $\mathrm{m}_{1}{ }^{\prime}$ & 0.072 & 0.791 & 0.25 e- 3 & 0.9999 \\
\hline & $\mathrm{p}$ & 0.912 & -0.384 & 0.05 e- 3 & 1.0000 \\
\hline \multirow{2}{*}{$\begin{array}{c}z_{11} \\
\text { (99 obs.) }\end{array}$} & $\mathrm{m}_{1}{ }^{\prime}$ & 0.079 & 0.791 & 0.19 e- 3 & 0.9999 \\
\hline & $\mathrm{p}$ & 0.903 & -0.382 & 0.04 e-3 & 1.0000 \\
\hline
\end{tabular}

NOTE. - Forecasting rules are conditional on current productivity, $\mathrm{z}_{\mathrm{i}}$. Each regression takes the form: $\log (\mathrm{y})=\beta_{1}+\beta_{2} \log \left(\mathrm{m}_{1}\right)$, where $\mathrm{y}=\mathrm{m}_{1}$ ' or $\mathrm{p}$. 